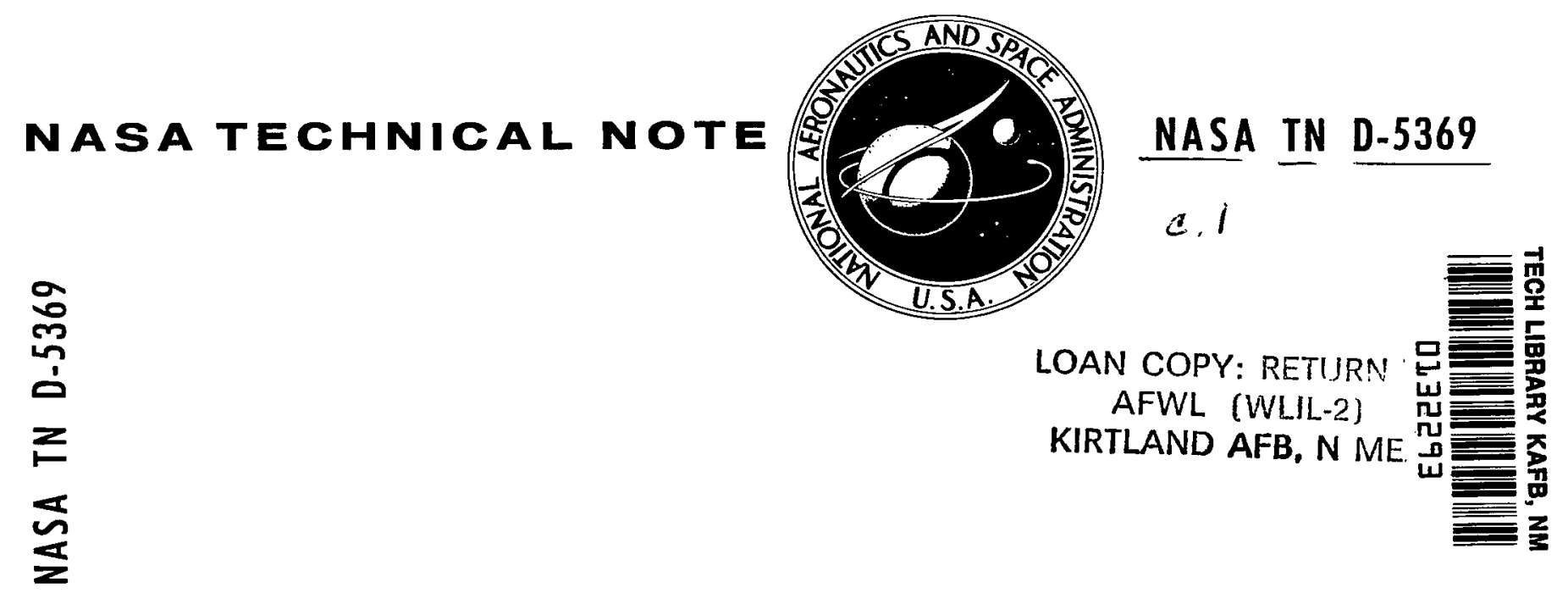

\title{
DESIGN OF EXPERIMENTS AS "DOUBLY TELESCOPING" SEQUENCES OF BLOCKS WITH APPLICATION TO A NUCLEAR REACTOR EXPERIMENT
}

by Arthur G. Holms and Steven M. Sidik

Lewis Research Center

Cleveland, Obio

NATIONAL aERONAUTICS AND SPACE ADMINISTRATION - WASHINGTON, D. C. - AUGUST 1969 
By Arthur G. Holms and Steven M. Sidik

Lewis Research Center

Cleveland, Ohio

NATIONAL AERONAUTICS AND SPACE ADMINISTRATION 


\section{ABSTRACT}

A blocked two-level factorial experiment was designed to measure the radiolysis of water. Effects of controlled variables are biased by changes in radiation with time and by equipment changes between fuel cycles; the experiment is therefore doubly confounded. Experimenting is subject to unplanned curtailments with respect to the first bias, and might be expanded with respect to the second. So that the more important parameters can be estimated free of biases ordinarily resulting from the indefinite size of the experiment, the rationale is given for arranging the blocks of the experiment in a "doubly telescoping" (orthogonally blocked) sequence. 


\title{
DESIGN OF EXPERIMENTS AS "DOUBLY TELESCOPING" SEQUENCES OF BLOCKS WITH APPLICATION TO A NUCLEAR REACTOR EXPERIMENT
}

\author{
by Arthur G. Holms and Steven M. Sidik \\ Lewis Research Center
}

\begin{abstract}
SUMMARY
An experiment was designed for observing the time-related pressure rise due to radiolytic decomposition of water in sealed capsules in a nuclear reactor. The effects of eight controlled variables are to be observed and expressed as the parameter estimates of a model equation. The levels of some of the variables will be changed from time to time during a single fuel burning cycle; however, there is a change in the radiation component levels with the amount of fuel burned, so that some of the parameter estimates are biased by (confounded with) the effects of the amount of fuel burned (which therefore constitute one source of block effects).

The levels of the controlled variables must be changed from one cycle to the next. Because of the possibility of equipment or instrument changes between one group of cycles and another, the design of the experiment must allow for this second source of block effects; that is, it must allow for double confounding.

Because of several types of operating problems, cycles are often stopped short of the intended operating time, and thus the size of the experiment is indefinite with respect to the first source of block effects. If the experimenting has been limited by cycle curtailments so that additional data is desired, or if the experimenter wishes to increase the scope of the estimated parameters, then additional cycles should be run at new conditions, and this could represent an expansion with respect to the second source of block effects. Thus a strategy of experimenting is needed wherein curtailments with respect to one type of block effects and expansions with respect to another can be accepted without the more important parameter estimates being biased by the time effects. (as they would be in a conventionally balanced design). The appropriate strategy will be called "double telescoping, " and the necessary statistical considerations together with an appropriate design are described.
\end{abstract}




\section{INTRODUCTION}

The particular problem needing experimental investigation is the time-related pressure rise due to radiolytic decomposition of water in sealed capsules in a nuclear reactor. The effects of eight variables on the pressure rise are to be observed in the NASA Plum Brook Nuclear Reactor Facility. The levels of some of the variables will be changed from time to time during a single fuel burning cycle. The nature of the radiation changes with the consumption of the fuel (uranium). This change introduces one source of block effects into the experiment.

The levels of the variables will also be changed from one cycle to the next. There exists a possibility that equipment or instrument changes may be made between cycles. This possibility introduces the second source of block effects so that the design of the experiment should allow for double confounding.

Five of the variables, the "fluid variables, "will be adjusted during the progress of a cycle. Because of several types of reactor operating problems, cycles are often stopped short of the full intended time. In such cases, the combination of "missing data" and confounding could induce severe biases into the parameter estimates.

Three of the variables, the "mechanical variables, "can be adjusted only between cycles. If the experimenter discovers that the conditions chosen for the experiment were other than ideal, he may wish to terminate the experiment possibly at the smallest number of cycles that will salvage only the main effect parameters. On the other hand, if the experimenting has been limited by cycle curtailments so that additional data is desired, or if the experimenter desires to estimate two factor interaction parameters among the mechanical variables, then the experiment should be expanded to include additional cycles at new conditions.

Thus, a strategy of experimenting is needed wherein curtailments of the experiment with respect to one source of block effects and expansions with respect to another can be accepted without the parameter estimates being biased by the time effects. Designs that give protection against single confounding have been called telescoping ( $\mathrm{ref} .6$ ). The double confounding requires double telescoping.

The current literature deals only with single telescoping. An important early contribution dealt with the performance of fractions of two level fixed effects experiments in sequences with parameters being estimated at various stages of completion of the total experiment (Daniel, ref. 1). The terms "expansible" and "contractible" were applied to related designs by Webb (ref. 2). Sequences of irregular fractions were discussed by John (ref. 3). The general subject was developed by Addelman (refs. 4 and 5). Detailed designs of regular fractions were described in reference 6 under the name of "telescoping sequences of blocks."

Whereas the current literature on telescoping sequences of blocks deals with single 
confounding and single telescoping, the immediate problem of the reactor experiment required that double confounding and double telescoping be considered. This experiment design problem on eight variables will be discussed from the point of view of the basic statistical considerations so that the reader will be able to produce doubly telescoping sequences of designs for other numbers of variables when faced with the problem of double confounding.

The sequence of designs has been formulated with the idea that the minimum design is sufficient to estimate all of the main effect parameters and that the maximum contemplated sequence is sufficient to estimate almost all of the two factor interactions. Such a design also provides estimates of some of the three factor and higher order interaction parameters. This fact can be used to advantage if the experimenter has some prior knowledge of the interactions. He can then perform a strategic matching of the names of the physical variables to the letters that stand for the independent variables of the design. This should be done so that those interactions that are known to be negligible will be the interactions confounded with block effects. Those interactions that are likely to be important, according to prior knowledge, should be the interactions that become estimable at the earliest possible stage of the sequence of experiments.

The telescoping parts of the design are presented as tables that give the combinations of the levels at which the factors should be set within the blocks.

\section{SYMBOLS}
A, B, C, D, E
fluid variables
$\mathrm{C}(\mathrm{k})$
group of defining contrasts for $2^{\mathrm{k}-1}$ blocks
$\mathrm{C}(\mathrm{r}, \mathrm{c})$
group of defining contrasts for $r$ row and c column blocks
c
number of column blocks
F, G, H
mechanical variables
I
identity contrast
$\mathbf{k}$
stage of experimenting; at any stage, number of blocks is $2^{\mathrm{k}-1}$ where $\mathrm{k}=1,2, \ldots$
$l$
$p-q$
$\mathrm{p}$
number of independent variables
q
one block contains $(1 / 2)^{\mathrm{q}}$ of the treatments of a full factorial experi- ment
$\mathbf{R}$
resolution level 


$\begin{array}{ll}\mathbf{r} & \text { number of row blocks } \\ \mathrm{T}(\mathrm{k}) & \text { group of treatments for } 2^{\mathrm{k}-1} \text { blocks } \\ \mathrm{Y} & \text { random response variable } \\ \mathrm{Y} & \text { observed value of } \mathrm{Y} \\ \beta & \text { unknown population parameter } \\ \gamma & \text { maximum number of letters in defining contrast group } \\ \epsilon & \text { single observation error } \\ \lambda & \text { number of factors in highest order interaction requiring estimation } \\ \sigma^{2} & \text { variance of } \epsilon \\ \tau & \text { number of factors in lowest order interaction allowed as an alias of interaction } \\ & \text { to be estimated }\end{array}$

\section{SOLUTION OF THE GENERAL PROBLEM}

In brief, the purpose of the experiment is to estimate the coefficients in an equation that is assumed to represent the response as a function of the independent variables. The function together with the assumptions about the experimental error are called the model. The error of any particular observed response is called $\epsilon$, and it is assumed to have mean zero and constant variance $\sigma^{2}$.

The coefficients of the model equation are assumed to be initially unknown and as such are called parameters. The unknown parameters are represented by the symbol $\beta$. The performance of an experiment leads to numbers (estimates) that are assumed to approximate the true values of the parameters, and the error in the approximations is assumed to decrease with increasing numbers of observations. The estimates of the parameters are ordinarily obtained by the method of least squares. The parameters that can be estimated from the experiments to be described can be estimated by Yates' method (ref. 7), which is a convenient technique within the method of least squares. Estimation of $\sigma^{2}$ is outside the scope of the present discussion.

An example of a model equation is

$$
\begin{aligned}
& \mathrm{Y}=\beta_{\mathrm{I}}+\beta_{\mathrm{A}} \mathrm{x}_{\mathrm{A}}+\beta_{\mathrm{B}} \mathrm{x}_{\mathrm{B}}+\cdots+\beta_{\mathrm{p}} \mathrm{x}_{\mathrm{p}} \\
& +\beta_{\mathrm{AB}} \mathrm{x}_{\mathrm{A}^{\mathrm{x}}} \mathrm{x}+\beta_{\mathrm{AC}} \mathrm{x}^{\mathrm{x}} \mathrm{x}^{+}+\cdot+\beta_{\mathrm{p}-1, \mathrm{p}^{\mathrm{x}} \mathrm{p}-1} \mathrm{x}_{\mathrm{p}} \\
& +\beta_{\mathrm{ABC}} \mathrm{x}^{\mathrm{x}} \mathrm{B}^{\mathrm{x}} \mathrm{C}+\cdots+\beta_{\mathrm{p}-2, \mathrm{p}-1, \mathrm{p}^{\mathrm{x}} \mathrm{p}-2^{\mathrm{x}} \mathrm{p}-1^{\mathrm{x}} \mathrm{p}} \\
& +\cdots+\epsilon
\end{aligned}
$$


where the $\beta^{\prime}$ 's are the parameters to be estimated and the $\mathrm{x}$ 's are the independent variables. The parameter $\beta_{I}$ is called the constant term. The parameters with a single subscript are called main effects, and they give the magnitude of the first-degree effects on the response to the independent variables. The parameters with more than one subscript are called interactions, and they represent the fact that the response to one independent variable depends on the level of one or more other independent variables.

\section{Notation for Treatments and Defining Contrasts}

A combination of levels of the independent variables is called a treatment. The notation for the treatments is illustrated by the first eight rows of table $\mathrm{I}$. The independent variables, which are written $x_{A}, x_{B}, x_{C}$, etc., can be standardized (coded) so that the upper level can be represented by $x_{A}=+1, x_{B}=+1, x_{C}=+1$, etc. and the lower level by $x_{A}=-1, x_{B}=-1, x_{C}=-1$, etc. Another notation for the levels of the independent variables is to use a 1 if the variable is at its lower level and to use the associated lower case letter if the variable is at its upper level. The equivalence of the notations is illustrated by the following example of a treatment:

$$
\left(\mathrm{x}_{\mathrm{A}}, \mathrm{x}_{\mathrm{B}}, \mathrm{x}_{\mathrm{C}}, \mathrm{x}_{\mathrm{D}}\right)=(1,1,-1,1)=\mathrm{ab} 1 \mathrm{~d}=\mathrm{abd}
$$

The particular design to be described uses blocks of size 8. The construction of the design therefore begins with a listing of the treatments of a full $2^{3}$ factorial design. The treatments are listed in Yates' standard order as shown by the first eight rows of the first column of table I. The second column stands for observed responses that correspond to treatments in the same row of the table. The third column presents a dummy variable that takes the value one. The array consisting of those columns headed by $\mathrm{A}$, $B$, and $\mathbf{C}$ is called the design matrix, and it gives, respectively, the levels of the variables $x_{A}, x_{B}$, and $x_{C}$. The design matrix therefore gives the same information as the single column headed "Treatments."

The array, beginning with the column headed $I$ and including all columns to the right, is called the matrix of independent variables. The columns of this matrix are regarded as column vectors. A special rule is used to perform multiplication of the columns. A column headed by $\mathrm{AB}$, for example, is the result of multiplying elements together from like rows of $A$ and $B$. (This rule of multiplying $A$ by $B$ to generate the column vector $\mathrm{AB}$ differs from the definitions of scalar product and vector product in conventional vector analysis. )

Inspection of table I shows that the multiplication of any column in the matrix of independent variables by itself generates the column headed $\mathrm{I}$. This fact means that com- 
plicated column multiplications can lead to simply stated results; for example,

$$
(\mathrm{ABC})(\mathrm{ACD})=\mathrm{A}^{2} \mathrm{BC}^{2} \mathrm{D}=\mathrm{IBID}=\mathrm{BD}
$$

The column vectors give the linear combinations of observations (provided the observations are in Yates' order) that estimate the coefficient indicated by the column heading. Because it prescribes the linear combination as a series of plus and minus ones, the column (or its heading) will be called a contrast. For the design of table I, the constant term $\beta_{\mathrm{I}}$ is estimated by multiplying the observations under "response" by the quantities under $I$ and summing and dividing by $2^{l}$ where for three variables $l=3$. If the quantities under "response" are multiplied in the same order, by the quantities under $A$, their sum divided by $2^{l}$ gives the change in response for a unit change in $x_{A}$, and this quotient is the estimator $\mathrm{b}_{\mathrm{A}}$ of the parameter $\beta_{\mathrm{A}}$. Likewise, multiplying the responses by the quantities of any column of the matrix of independent variables and dividing the sum by $2^{l}$ estimates the coefficient parameter subscripted by the column heading. The computations can be done easily, and in an organized manner, using Yates' algorithm (ref. 7), which gives the results in the order of the column headings of the matrix of independent variables.

\section{Telescoping Blocks}

Parts of an experiment are sometimes performed in a sequence over differing time segments, over differing batches of raw material, or over differing pieces of equipment. The experimental units within the part are assumed to be relatively uniform within the part and such a part, or the set of treatments assigned to it, is called a block. The conditions that differ from one part to the next are assumed to effect the response by amounts that are not readily predicted or controlled. The responses to changes between the parts of the experiment are called block effects. Experiments designed to estimate the parameters of the model equation without contamination from block effects are called orthogonally blocked designs. When a sequence of orthogonal blocks is designed so that observations from the first few blocks may be used to estimate the coefficients of a simple model and then be retained and combined with observations from new blocks so that all acquired observations are used cumulatively to estimate models of successively greater and greater generality, the blocks will be said to form a telescoping sequence.

\section{Use of Group Theory}

The notation and theory to be used in choosing the defining contrasts for the sequence 
of blocks will be that of the theory of finite commutative groups (ref. 11). An experiment is said to be at the $\mathrm{k}^{\mathrm{th}}$ stage of telescoping if it contains $2^{\mathrm{k}-1}$ blocks. The treatment group at the $\mathrm{k}^{\text {th }}$ stage of experimenting is represented by $T(k)$. Thus, where the number of factors is $p$ and the number of treatments in a block is $2^{p-q}$, the number of blocks in a full factorial experiment is $2^{q}$, and it is achieved at the $q+1$ stage. The treatment combination group for the full factorial experiment is written $T(q+1)$, and it is the set of the first $p$ lower case Roman letters and all possible products, where multiplication is the usual multiplication subject to $\mathrm{a}^{2}=\mathrm{b}^{2}=\ldots .=1$. Thus, $\mathrm{T}(\mathrm{q}+1)$ includes all the treatment combinations that could be performed in a full factorial experiment.

The defining contrast group at the $\mathrm{k}^{\text {th }}$ stage of the experimenting is represented by $\mathrm{C}(\mathrm{k})$. Thus, the contrast group $\mathrm{C}(0)$ is defined as the first $\mathrm{p}$ upper case Roman letters and all their products subject to $\mathrm{A}^{2}=\mathrm{B}^{2}=\ldots .=\mathrm{I}$.

Two elements of either a treatment group or a contrast group are said to be orthogonal if the number of letters they have in common is even. For example, abd is orthogonal to bde. This definition is extended to the orthogonality of an element of one group with that of another, and thus $\mathrm{ABD}$ is orthogonal to bde. As applied, this type of orthogonality is achieved with "the rule of even numbers." Its use is discussed in section 9.31 of reference 7 .

If a subgroup $\mathrm{T}(\mathrm{k})$ of the treatment group is chosen, then there is a subgroup $\mathrm{C}(\mathrm{k})$ of the contrast group $C(0)$ such that every element of $T(k)$ is orthogonal to the elements of $\mathrm{C}(\mathrm{k})$ and vice versa. Group $\mathrm{C}(\mathrm{k})$ is called the alias group or the defining contrast group and as such provides the information that shows which parameters are aliased when estimates are formed from observations resulting from the performance of the treatment group $\mathrm{T}(\mathrm{k})$.

The order of $T(k)$ (written $0(T(k))$ ) is defined as the number of elements in $T(k)$ and it is the number of treatments, which is $2^{p-q+k-1}$. The order of $C(k)$ is written $0(\mathrm{C}(\mathrm{k}))$ and is defined as the number of contrasts (including $\mathrm{I}$ ) contained in $\mathrm{C}(\mathrm{k})$ - namely, $2^{2-k+1}$. Then, $T(k)$ constitutes a $2^{k-q-1}$ fraction of the full factorial experiment. The alias subgroup (the defining contrasts) $\mathrm{C}(\mathrm{k})$ can be generated by multiplying $\mathrm{q}-\mathrm{k}+1$ independent elements of $\mathrm{C}(\mathrm{k})$ together in all possible combinations. (A set of elements contains only independent elements if there is no multiplicative combination of them that produces I.)

If the first block of a blocked experiment on $p$ factors is considered as a $2^{-q}$ fractional replicate with $2^{l}$ treatments, then $l=p-q$ and the aliased combinations of parameters that can be estimated are determined by the $C(1)$ that is orthogonal to the $T(1)$ of the first block.

If a subgroup $\mathrm{C}(\mathrm{k})$ of the contrast group $\mathrm{C}(1)$ is used as the defining contrast group of an experiment with $2^{\mathrm{k}-1}$ blocks, then the $2^{\mathrm{k}-1}$ blocks will constitute a regular fractional replicate of the $2^{p}$ experiment, and there will be some main effect or interaction 
parameters confounded with parameters representing mean responses for the different blocks. The parameters confounded are represented by the contrasts contained in $\mathrm{C}(1)$. Those contrasts contained in $C(\mathrm{k})$ represent parameters that are confounded with the grand mean. The aliased combinations of main effect and interaction parameters that are confounded with block parameters (other than the grand mean) are indicated by the complement of $\mathrm{C}(\mathrm{k})$ with respect to $\mathrm{C}(1)$.

Blocks are added in stages so that at each stage the design is a regular fractional replicate, and this condition implies that at each stage the defining contrast groups are subgroups of the previous group. Double or multiple telescoping occurs at any stage when more than one subgroup is selected from the group for the previous stage.

\section{Resolution Levels}

The full factorial experiment with conditions fixed at all combinations of just two levels of $\mathrm{p}$ independent variables (factors) permits the estimation of parameters representing the constant term, the first-order (main) effects of the factors, and the results of factors interacting two at a time, three at a time, and in all combinations up to $p$ at a time. If a fraction $(1 / 2)^{q}$ of this experiment is performed, not all these parameters can be estimated. True response surfaces in physical investigations are typically smooth enough that the coefficients of the higher order terms of an approximating polynomial equation may be assumed negligible over a small enough range of the experimentation. Accordingly, only the lower order coefficients are estimated, and they are allowed to be biased by (aliased with) coefficients of higher order interactions because such coefficients are assumed to be negligible. A parameter of any order is called estimable if its estimate contains no aliased parameters, unless they are of higher order. Let the number of factors in the highest order interaction requiring estimation be $\lambda$, and let the number of factors in the lowest order interaction with which it is allowed to be aliased be $\tau$; then, the required resolution $R$ of the design is defined (ref. 8 ) to be

$$
\mathbf{R}=\lambda+\tau
$$

As a minimum requirement on the first stopping point of an experiment, the first-order parameters are required to be estimable. They are allowed to be aliased with only the coefficients of two-factor or higher order interactions. This requires that $R=\lambda+\tau$ $=1+2=3$. A somewhat improved design occurs if the first-order coefficients are estimated clear of two-factor interactions. This requires that $R=\lambda+\tau=1+3=4$.

The requirement on the total experiment is that any possibly important two-factor interaction coefficients should be estimable (allowed to be aliased only with three-factor or higher order interaction coefficients). This requires that $R=\lambda+\tau=2+3=5$. 


\section{Defining Contrasts for the First Block}

The approach to the general problem of double telescoping in the presence of double confounding is now illustrated for a problem with eight independent variables (factors) and with blocks consisting of eight treatments per block. Because it contains eight treatments, the first block may be regarded as a full two-level factorial experiment on factors $\mathrm{A}, \mathrm{B}$, and $\mathrm{C}$, which is to be modified by the inclusion of factors $\mathrm{D}, \mathrm{E}, \mathrm{F}, \mathrm{G}$, and H. The contrasts for $\mathrm{D}, \mathrm{E}, \mathrm{F}, \mathrm{G}$, and $\mathrm{H}$ must be equated to some of the interaction contrasts of the full factorial experiment on $A, B$, and $C$.

Experimenters sometimes desire that the first block contain a set of "standard conditions, "which is assumed to be the treatment combination for which all variables are at their low levels. The block containing such a treatment is called the principal block. It is obtained by setting a new contrast equal to an existing contrast, if the existing contrast contains an odd number of letters, and by setting a new contrast equal to the negative of an existing contrast, if the existing contrast contains an even number of letters.

The equating of contrasts $\mathrm{D}, \mathrm{E}, \mathrm{F}, \mathrm{G}$, and $\mathrm{H}$ to existing contrasts involving $\mathrm{A}$, $\mathrm{B}$, and $\mathrm{C}$ could be done, for example, as follows:

$$
\left.\begin{array}{l}
\mathbf{D}=\mathbf{B} \\
\mathbf{E}=-A C \\
\mathbf{F}=-A B \\
\mathbf{G}=\mathbf{C} \\
\mathrm{H}=\mathrm{ABC}
\end{array}\right\}
$$

These choices are equivalent to the selection of the following set of independent defining contrasts:

$$
\mathrm{I}=\mathrm{BD}=-\mathrm{ACE}=-\mathrm{ABF}=\mathrm{CG}=\mathrm{ABCH}
$$

Other assignments of $A, B$, and $C$ could have been made to $D, E, F, G$, and $H$. Assignments are equivalent if the orders of the estimable coefficients are the same and if the numbers of estimable coefficients of any given order are the same. If the orders or numbers of estimable coefficients of any given order are not the same, the assignments are called nonequivalent.

The elements of a set of independent defining contrasts are called the generators. If the generators are multiplied together in all possible combinations, the complete group is generated as illustrated by the first column of table II, which was generated from the independent defining contrasts listed in equation (2). 


\section{Nonequival ent Independent Defining Contrasts for the First Block}

The proposed experiment uses a first block of size $2^{l}=2^{3}=8$. Therefore,

$$
\begin{gathered}
0(\mathrm{C}(1))=2^{\mathrm{p}-\imath}=2^{8-3}=2^{5}=32 \\
q=\mathrm{p}-\imath=8-3=5
\end{gathered}
$$

and $\mathrm{C}(1)$ contains five independent generators. Independence may be assured by using any combinations of $A, B$, and $C$ combined with $D, E, F, G$, and $H$ with the latter being used only one at a time. The independent defining contrasts are therefore represented by

$$
\text { .. D, . E E, . F . . G G, . } \mathrm{F}
$$

where . . represents combinations of $\mathrm{A}, \mathrm{B}$, and $\mathrm{C}$. An example is

$$
\mathrm{BD}, \mathrm{CE}, \quad-\mathrm{ABF}, \quad-\mathrm{ACG}, \quad \mathrm{ABCH}
$$

The properties that are possessed by a sequence of telescoping blocks are partly determined by the number $\mathrm{I}_{0}$ of independent defining contrasts containing none of $\mathrm{A}, \mathrm{B}$, or $C$; the number $I_{1}$ containing just one of $A, B$, and $C$, the number $I_{2}$ containing just two of $\mathrm{A}, \mathrm{B}$, and $\mathrm{C}$; and the number $\mathrm{I}_{3}$ containing all of $\mathrm{A}, \mathrm{B}$, and $\mathrm{C}$. The properties of the preceding example will thus be partly determined by

$$
\left(I_{0}, I_{1}, I_{2}, I_{3}\right)=(0,2,2,1)
$$

Even if the set of five independent defining contrasts is not that of the preceding specific example but is to be characterized by

$$
\left(I_{0}, I_{1}, I_{2}, I_{3}\right)=(0,2,2,1)
$$

then nevertheless $A B C$ must still be one of the multipliers. The fact that $I_{2}=2$ requires that two of the combinations $\mathrm{AB}, \mathrm{AC}$, and $\mathrm{BC}$ must be chosen as multipliers. When the choice has been made, two of $A, B$, and $C$ will have been used singly and one will have been used twice. The satisfaction of $I_{1}=2$ requires that two of $A, B$, and $C$ be used singly. If they are the letters that were used singly for $\mathrm{I}_{2}$, the defining contrasts could be $\mathrm{BD}, \mathrm{CE},-\mathrm{ABF},-\mathrm{ACG}$, and $\mathrm{ABCH}$.

The requirement of $I_{1}=2$ could have been met using only one of the letters that had been used singly for $I_{2}$. The defining contrasts could be $A D, B E,-A B F,-A C G$, and 
$\mathrm{ABCH}$ or $\mathrm{AD}, \mathrm{CE},-\mathrm{ABF},-\mathrm{ACG}$, and $\mathrm{ABCH}$. In the first of the two preceding cases, interchanging $B$ with $C$ and $F$ with $G$ produces the second case. These cases are therefore equivalent under a permutation of letters.

Thus, if

$$
\left(I_{0}, I_{1}, I_{2}, I_{3}\right)=(0,2,2,1)
$$

the nonequivalent cases may be represented by

$$
\mathrm{I}=\mathrm{BD}=\mathrm{CE}=-\mathrm{ABF}=-\mathrm{ACG}=\mathrm{ABCH}
$$

and

$$
\mathrm{I}=\mathrm{AD}=\mathrm{CE}=-\mathrm{ABF}=-\mathrm{ACG}=\mathrm{ABCH}
$$

\section{Defining Contrasts for a Doubly Telescoping Sequence}

Addelman (ref. 4) has given an expression for the maximum number of letters $\gamma$ that appear in a defining contrast group for a $1 / 2^{q}$ replicate of the full $2^{p}$ factorial design. The expression is

$$
\gamma=p\left(2^{q-1}\right)
$$

Consideration of an appropriate set of eight blocks of the proposed experiment shows it to be a $1 / 2^{2}$ replicate of a full $2^{8}$ experiment so that $p=8$ and $q=2$ and thus

$$
\gamma=8\left(2^{2-1}\right)=16
$$

With $q=2$ there will be two independent defining contrasts or (not counting I) there will be a total of three defining contrasts to be made up of the allowable 16 letters. The maximum resolution level is therefore achieved if the three defining contrasts consist of words of length $(5,5,6)$.

The defining contrasts for the first block had been generated as the first column of table II from the independent defining contrasts occurring in equation (2). Subgroups of that column are to be chosen to define the treatments for several options of telescoping. A notation is needed for the subgroups. Let a subgroup be represented by $C(r, c, p, q)$ where $r$ is the number of row blocks, $c$ the number of column blocks, $p$ the number of factors, and $2^{-\mathrm{q}}$ the fraction of the full two-level factorial experiment represented by the first block. In particular cases, not all of $r, c, p$, and $q$ need be identified. In the 
present example, $p$ is fixed at 8 and $q$ is fixed at 5 and so the notation for a contrast group is simplified to $\mathrm{C}(\mathrm{r}, \mathrm{c})$.

The initial specification is that any $1 / 2$ replicate of the experiment shall be at least of resolution 5 . The possible $1 / 2$ replicates are represented by contrast groups having rows and columns of blocks (see fig. 1) as follows: $\mathrm{C}(1,16), \mathrm{C}(2,8), \mathrm{C}(4,4), \mathrm{C}(8,2)$, and $\mathrm{C}(16,1)$. Each of these contrast groups is to contain $\mathrm{I}$ and a single generator with a word length of at least 5 . Such $1 / 2$ replicate experiments can be achieved by doubling the size of $1 / 4$ replicates. The defining contrast groups for each $1 / 4$ replicate must contain both of the contrast groups for the $1 / 2$ replicates into which the $1 / 4$ replicate can be expanded. In order that the $1 / 4$ replicates be of maximum possible resolution level, the defining contrasts for the $1 / 2$ replicates should be such that those pairs that must be multiplied will produce words of maximum length.

The preceding criteria suggest that acceptable defining contrasts, which generate the chain of telescoping designs, are as underlined in the following defining contrast groups:

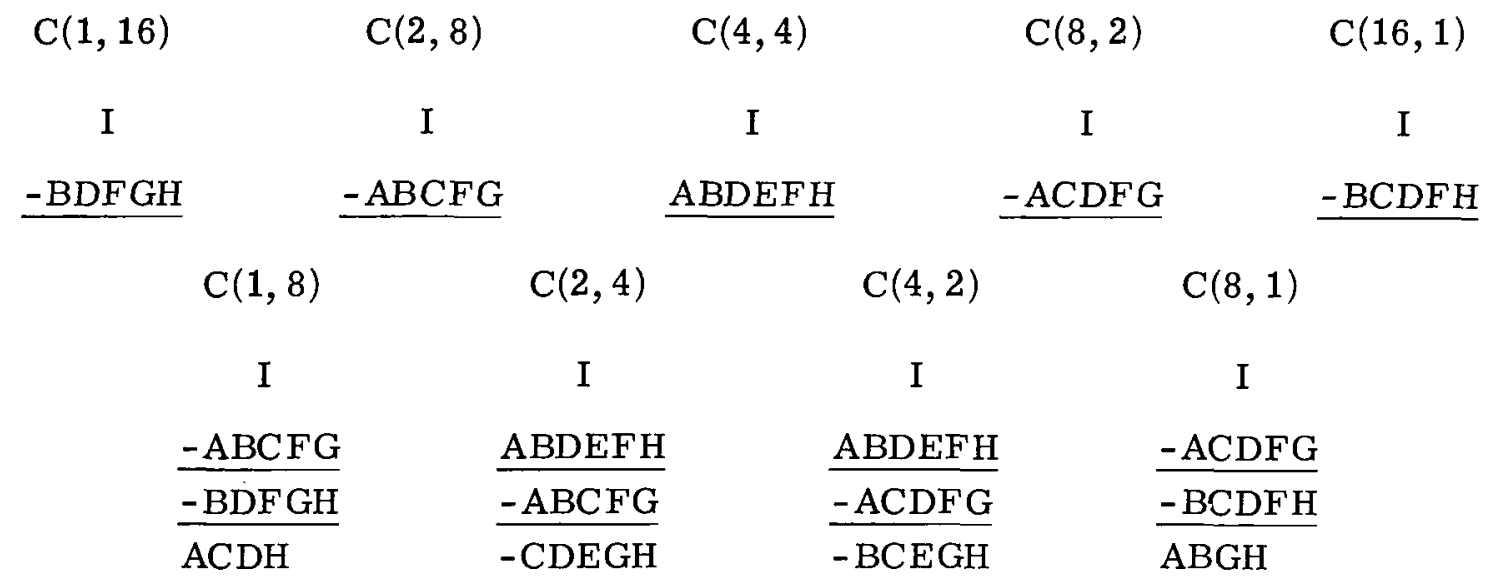

The preceding lists show that the choices of the $1 / 2$ replicates have led to two resolution five and two resolution four $1 / 4$ replicates.

Combining groups from the preceding list gives the defining contrasts for the $1 / 8$ replicates as follows:

\begin{tabular}{|c|c|c|}
\hline$C(1,4)$ & $C(2,2)$ & $\mathrm{C}(4,1)$ \\
\hline I & I & I \\
\hline ABDEFH & ABDEFH & ABDEFH \\
\hline -ABCFG & -ACDFG & -ACDFG \\
\hline$\overline{-C D E G H}$ & $\overline{-B C E G H}$ & $\overline{-B C E G H}$ \\
\hline -BDFGH & - $\mathrm{ABCFG}$ & -BCDFH \\
\hline$-A E G$ & - CDEGH & $-\mathrm{ACE}$ \\
\hline $\mathrm{ACDH}$ & $\mathrm{BD}$ & ABGH \\
\hline BCEF & AEFH & DEFG \\
\hline
\end{tabular}


From the preceding lists $C(1,4)$ and $C(2,2)$ are combined to produce $C(1,2)$, and $C(2,2)$ and $C(4,1)$ are combined to produce $C(2,1)$ :

$\mathrm{C}(1,2)$ : I, ABDEFH, -ACDFG, -BCEGH, -ABCFG, -CDEGH, BD, AEFH, -BDFGH, -AEG, ABCH, CDEF, ACDH, BCEF, -FGH, -ABDEG.

$\mathrm{C}(2,1)$ : I, ABDEFH, -ACDFG, -BCEGH, -ABCFG, -CDEGH, BD, AEFH, -BCDFH, -ACE, ABGH, DEFG, ADGH, BEFG, -CFH, -ABCDE.

Combining $\mathrm{C}(2,1)$ with $\mathrm{C}(1,2)$ gives $\mathrm{C}(1,1)$ as listed in the first column of table II.

The resolution levels achieved at the several stages of telescoping were as follows:

\begin{tabular}{|l|c|} 
Replicate & Resolution numbers \\
$1 / 32$ & 2 \\
$2 / 32$ & 2,2 \\
$4 / 32$ & $3,2,3$ \\
$8 / 32$ & $4,5,5,4$ \\
$16 / 32$ & $5,5,6,5,5$ \\
\hline
\end{tabular}

The possibility exists that some other set of defining contrasts for $C(1,1)$ or some other choice of the subgroups of $\mathrm{C}(1,1)$ could lead to an improved sequence of resolution numbers.

\section{Crossed Blocking}

The subject of double confounding can be discussed from the point of view of two types of models for the block effects. One type is called nested blocking. An example of this type is given in reference 7 (p. 582). In the example, each of four units of a plant constitutes a block. Furthermore, if experimenting is done on each of two days, then the experimenting during one day is in a different block from the experimenting performed on another day. The blocking over days is thus nested within the blocking over units.

The particular problem that motivated the present investigation does not involve the nested type of double confounding but instead involves a type called crossed blocking. The general assumption of crossed blocking is defined to mean that there is an effect of column blocks, an effect of row blocks, and an effect of row column interaction. The degrees of freedom for block effects would be as follows:

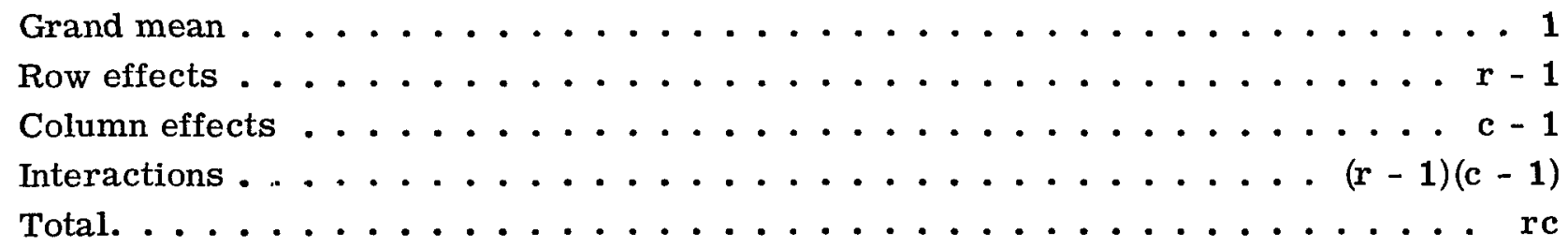


In the discussion that follows, the grand mean is regarded as one of the block effects. Thus, in the case of crossed blocking with interactions between row and column effects, the total number of block effects for an experiment with $r$ rows and $c$ columns of blocks is $\mathrm{rc}$, and this is the number of estimates confounded with block effects. At the $\mathrm{k}^{\text {th }}$ stage of telescoping (where $\mathrm{k}=1$ for the first block)

$$
r c=2^{\mathrm{k}-1}
$$

The number of defining contrasts for the fractional replication at the $\mathrm{k}^{\text {th }}$ stage of the telescoping is $2^{\mathrm{q}-\mathrm{k}+1}$, and this is the number of parameters occurring in any aliased set. Thus, the total number of parameters aliased together and confounded with blocks is equal to the product of the number of parameters aliased in any estimate and the number of estimates confounded with block effects. Under the assumption of crossed blocking with interactions, this product is

$$
r c 2^{q-k+1}=2^{k-1} 2^{q-k+1}=2^{q}
$$

Thus, at any stage of the telescoping the number of parameters confounded with block effects is equal to the number of defining contrasts for the first block. The specific parameter estimates confounded with row block effects, column block effects, and row column interactions must be determined.

\section{Identification of Parameters Confounded with Block Effects}

When the estimating is done with a regular fractional replicate consisting of $\mathrm{rc}$ blocks, then, where $\mathrm{C}(\mathrm{r}, \mathrm{c})$ is the group of defining contrasts for the rc blocks, the confounded parameter estimates are identified as follows:

(1) The defining contrasts contained in $\mathrm{C}(1, \mathrm{c})$ but not in $\mathrm{C}(\mathrm{r}, \mathrm{c})$ identify the parameter estimates confounded with row block effects.

(2) The defining contrasts contained in $\mathrm{C}(\mathrm{r}, 1)$ but not in $\mathrm{C}(\mathrm{r}, \mathrm{c})$ identify the parameter estimates confounded with column block effects.

(3) The defining contrasts contained in $\mathrm{C}(1,1)$, not contained in $\mathrm{C}(\mathbf{r}, 1)$, and not contained in $\mathrm{C}(1, \mathrm{c})$ identify the parameter estimates confounded with row column interaction block effects.

The identification of sets of aliased parameters that are confounded with block effects is illustrated for the $(4,2)$ experiment of the telescoping sequence that was just used to illustrate the defining contrasts for a doubly telescoping sequence.

If a $(4,1)$ experiment is expanded into a $(4,2)$ experiment, the defining contrasts of the $(4,1)$ experiment not contained in the defining contrasts of the $(4,2)$ experiment iden- 
tify the parameters confounded with the block differences between the two columns. Such a set of contrasts is denoted as $\mathrm{C}(4,1)-\mathrm{C}(4,2)$.

From the preceding tables (p. 12)

$$
\mathrm{C}(4,1)-\mathrm{C}(4,2)=-\mathrm{BCDFH},-\mathrm{ACE}, \mathrm{ABGH}, \mathrm{DEFG}
$$

The corresponding aliased set of parameters confounded with the column differences (as identified by the superscript) is

$$
\left(-\beta_{\mathrm{BCDFH}}-\beta_{\mathrm{ACE}}+\beta_{\mathrm{ABGH}}+\beta_{\mathrm{DEFG}}\right)^{\mathrm{c}}
$$

Because the $(4,2)$ experiment contains four rows and two columns, the row block effects are to be identified by comparison with a $(1,2)$ experiment. The contrasts identifying parameters confounded with row effects are therefore found from the preceding tables as

$\mathrm{C}(1,2)-\mathrm{C}(4,2)=-\mathrm{ABCFG},-\mathrm{CDEGH}, \mathrm{BD}, \mathrm{AEFH},-\mathrm{BDFGH}$,

-AEG, ABCH, CDEF, ACDH, BCEF, -FGH, -ABDEG

The manner in which the corresponding parameters are aliased is determined by the defining contrasts for the $(4,2)$ experiment; namely,

$$
\mathrm{C}(4,2)=\mathrm{I}, \mathrm{ABDEFH},-\mathrm{ACDFG},-\mathrm{BCEGH}
$$

and the aliased sets can be determined by multiplying elements of $C(1,2)-C(4,2)$ by the group $\mathrm{C}(4,2)$. Among such results, the unique aliased sets of parameters confounded with row effects are

$$
\begin{aligned}
& \left(-\beta_{\mathrm{ABCFG}}-\beta_{\mathrm{CDEGH}}+\beta_{\mathrm{BD}}+\beta_{\mathrm{AEFH}}\right)^{\mathrm{r}} \\
& \left(-\beta_{\mathrm{BDFGH}}-\beta_{\mathrm{AEG}}+\beta_{\mathrm{ABCH}}+\beta_{\mathrm{CDEF}}\right)^{\mathrm{r}} \\
& \left({ }^{+} \beta_{\mathrm{ACDH}}+\beta_{\mathrm{BCEF}}-\beta_{\mathrm{FGH}}-\beta_{\mathrm{ABDEG}}\right)^{\mathrm{r}}
\end{aligned}
$$

The preceding three sets of aliased parameters are the sets whose estimates are confounded with the differences among the four rows of blocks and thus correspond to the three degrees of freedom for row blocking.

As was previously demonstrated, the number of parameters confounded with block 
effects is equal to the number of defining contrasts for the first block. Thus the parameters confounded with row column interactions are identified by the elements of $\mathrm{C}(1,1)$ not already identified with the row or column block effects. These elements are the elements of $C(1,1)$ not contained in either $C(4,1)$ or $C(1,2)$; thus,

$$
\begin{aligned}
& C(1,1)-(C(4,1)+C(1,2))=-A B F, C G,-A B C D E,-A D F, \\
& \text { BCDG, -BEH, -CFH, -DEH, ADGH, BEFG, ACEFGH, ABCDEFGH }
\end{aligned}
$$

The aliased sets of parameters having estimates that are confounded with row column interactions are identified from the preceding list by multiplying elements by the group $\mathrm{C}(4,2)$. Among such results, the unique aliased sets are

$$
\begin{aligned}
& \left(-\beta_{\mathrm{ABF}}-\beta_{\mathrm{DEH}}+\beta_{\mathrm{BCDG}}+\beta_{\mathrm{ACEFGH}}\right)^{\mathrm{rc}} \\
& \left(\beta_{\mathrm{CG}}+\beta_{\mathrm{ABCDEFGH}}-\beta_{\mathrm{ADF}}-\beta_{\mathrm{BEH}}\right)^{\mathrm{rc}} \\
& \left(-\beta_{\mathrm{CFH}}-\beta_{\mathrm{ABCDE}}+\beta_{\mathrm{ADGH}}+\beta_{\mathrm{BEFG}}\right)^{\mathrm{rc}}
\end{aligned}
$$

The preceding aliased sets of parameters correspond to the degrees of freedom for the row column interaction:

$$
(r-1)(c-1)=(4-1)(2-1)=3
$$

If the block interaction effects were assumed to be negligible (if the model for block effects was assumed to be simply additive), then the three preceding aliased sets would correspond not to block effects but to estimates of the stated parameters.

The reactor experiment to be described is characterized by two special features:

(1) There is a constraint between one of the block effects and some of the variables; namely, the treatment levels of the mechanical variables cannot be changed along with the known important block effect.

(2) The crossed blocking may be assumed to be free of interactions; that is, the block effects exist only as column and row effects. The consequences of these special features are described in the next section. 


\section{SOLUTION OF THE PARTICULAR PROBLEM}

\section{Mechanical Variables Experiment}

There are three mechanical variables, and they have the symbols $F, G$, and $H$. Their main effects can be estimated with a $1 / 2$ replicate of a two-level full factorial experiment, which requires four treatments and therefore, four reactor cycles.

\section{Fluid Variables Experiment}

The time available during the reactor cycle allows for the performance of about 16 fluid variable treatments. The time periods of the reactor cycle are assumed to consist of eight blocks so that a single block of a single cycle will contain two treatments of the fluid variables. With four reactor cycles, a given time block contains eight fluid variable treatments. The operational meaning of this statement becomes clearer with the discussion of table XII.

The fluid variable treatments within the four reactor cycles are to be performed at fixed levels of the mechanical variables, and these fixed levels are chosen as the principal 1/2 replicate of a full factorial experiment on F, G, and $H$. For these three variables, the preferred defining contrast is that which aliases the highest order interaction, namely, FGH. The treatment levels of F, G, and $\mathrm{H}$ for each of the four cycles are thus (1), fg, fh, and gh. Because these treatment levels remain constant during adjustments of A, B, C, D, and E within cycles, the alias of FGH with the grand mean is not removed by the addition of the treatment levels of $\mathrm{A}, \mathrm{B}, \mathrm{C}, \mathrm{D}$, and $\mathrm{E}$. Therefore, FGH is necessarily one of the defining contrasts for the entire sequence of blocks for which the mechanical variables are fixed.

Thus, the $1 / 2$ replicate experiment on the three mechanical variables that is to be completed in four reactor cycles requires that one of the defining contrasts be the three letter word consisting of the mechanical variables - namely, FGH.

\section{Construction of the Double Sequence of Defining Contrast Groups}

A tentative group of defining contrasts for the $(1,1)$ replicate is listed in table II. The telescoping design that is intended to give protection against the block effect occurring during a reactor cycle is represented in figure 1 by the blocks in successive columns where the columns are numbered $j=1,2, \ldots, 8$. The corresponding sequences of fractional replicates are as follows: $(1,1),(1,2),(1,4)$, and $(1,8)$. 
If the experimenting within the first four cycles is curtailed or if the experiment is to be expanded for other reasons, a second row of blocks is to be performed. The first and second rows are identified by $\mathbf{i}=1$ and $\mathbf{i}=2$. The telescoping sequence of fractional replicates would then contain numbers of row and column blocks as follows: $(2,1)$, $(2,2),(2,4)$, and $(2,8)$ where $(2,8)$ is a $1 / 2$ replicate of the full factorial experiment.

As previously established, the defining contrasts for the $(1,8)$ experiment must include -FGH. The $(2,4)$ replicate does not have such a constraint and can therefore be of higher resolution. Its maximum possible resolution was shown to occur when the defining contrasts are words of lengths $(5,5,6)$. To be part of the telescoping sequence, and to be of maximum resolution level, the defining contrast for the $(2,8)$ experiment must consist of the six-letter word among the defining contrasts for the $(2,4)$ experiment, and this word must therefore appear along with -FGH in the three defining contrasts for the (1.8) experiment. Inspection of the $\mathrm{C}(1,1)$ contrasts of table II shows that these objectives can be achieved by selecting

$$
\mathrm{I}=-\mathrm{FGH}=-\mathrm{ABDEG}=\mathrm{ABDEFH} \quad \text { for } \mathrm{C}(\mathbf{1}, \mathbf{8})
$$

and

$$
\mathrm{I}=-\mathrm{ACDFG}=-\mathrm{BCEGH}=\mathrm{ABDEFH} \quad \text { for } \mathrm{C}(2,4)
$$

The obvious choice for $\mathrm{C}(2,8)$ is

$$
I=A B D E F H
$$

The next objective is to select a group of defining contrasts for $C(1,4)$ so that telescoping can be accomplished from it to either the $(1,8)$ experiment or to the $(2,4)$ experiment (fig. 1). This objective is attained by selecting $C(1,4)$ to contain both $C(1,8)$ and $\mathrm{C}(2,4)$. This is done by augmenting the independent defining contrasts of $\mathrm{C}(1,8)$ with one defining contrast from $\mathrm{C}(2,4)$ that is independent of the defining contrasts of $\mathrm{C}(1,8)$. Such a contrast is provided by -ACDFG, so that the generators of $\mathrm{C}(1,4)$ are $-\mathrm{FGH}$, -ABDEG, and -ACDFG. Multiplying these three generators together in all possible combinations generates $\mathrm{C}(1,4)$ as in table $I$.

The group $C(1,4)$ has been chosen to contain both $C(1,8)$ and $C(2,4)$. The group $C(2,2)$ must now be chosen so that it may be contained within a suitable $C(1,2)$ and within a suitable $C(2,1)$. The conditions on $C(1,2)$ and $C(2,1)$ are that $C(1,2)$ must contain $-F G H$ and $C(2,1)$ must not contain -FGH, and furthermore $C(1,2)$ and $C(2,1)$ should each be of maximum resolution level (hopefully not less than resolution 3 ). The group $C(2,2)$ can be generated by adding a third contrast to the generators of $C(2,4)$ (which are -ACDFG and -BCEGH) such that the third contrast is contained in $C(1,1)$ but not in 
$\mathrm{C}(1,4)$, and such that, when added to the generators of $\mathrm{C}(2,4)$, it will not generate $-\mathrm{FGH}$. The elements of $C(1,1)$ not contained in $C(1,4)$ that will not generate -FGH but which will generate resolution three designs are $-\mathrm{ACE},-\mathrm{ABF}, \mathrm{ABCH}$, and $-\mathrm{ABCDE}$. Any one of them might therefore be combined with the generators of $\mathrm{C}(2,4)$ to generate $C(2,2)$. The next step is to generate $C(1,2)$. Its generator must be an element of $C(1,1)$ not contained in $C(1,4)$ and not contained in $C(2,2)$, but hopefully it will be such that $\mathrm{C}(1,2)$ will be of resolution three.

Of the four possible generators for $\mathrm{C}(2,2)$ as previously listed, the first (namely, $-\mathrm{ACE})$ results in $\mathrm{C}(2,2)$ as follows:

$$
\text { I, -ACDFG, -BCEGH, ABDEFH, -ACE, DEFG, ABGH; - BCDFH }
$$

However, in anticipation of generating $\mathrm{C}(2,1)$, multiplication of this list by -ABF, $\mathrm{ABCH}$, or $-\mathrm{ABCDE}$ does not furnish a desirable list for $\mathrm{C}(2,1)$. An alternative is to generate $C(2,2)$ from $C(2,4)$ using - ABF. The result is listed for $C(2,2)$ in table III. Furthermore, a suitable list for $\mathrm{C}(2,1)$ results from multiplying this $\mathrm{C}(2,2)$ by $\mathrm{ABCH}$, as also listed in table III. The remaining objective is to construct $\mathrm{C}(1,2)$ so that it contains both $C(1,4)$ and $C(2,2)$. This is done by multiplying $C(1,4)$ by the generator used to generate $\mathrm{C}(2,2)$ from $\mathrm{C}(2,4)$ - namely, -ABF. The result is listed for $\mathrm{C}(1,2)$ in table II.

\section{IDENTIFICATION OF PARAMETER ESTIMATES}

\section{Aliased Sets of Parameters}

The telescoping sequence of designs is intended to provide estimates of all the firstorder parameters at an early stage of the experimentation. The completion of all the intended stages of a sequence should provide estimates of all two-factor interaction parameters that were not confounded with block effects. Such parameter estimates might be aliased with three-factor and higher order interaction parameters. In the absence of prior knowledge to the contrary, the experimenter would assume that in any aliased set, only the lowest order parameters could be significant. On the other hand, the experimenter might have prior knowledge that tells him, for example, that in an aliased set consisting of a two-factor interaction and a three-factor interaction, it is the particular three-factor interaction, rather than the particular two-factor interaction, that is significant. The aliased three-factor coefficients are therefore tabulated for all the larger designs (designs containing four or more blocks).

If a contrast does not estimate any combination of three-factor or lower order coefficients, the contrast is given a name by listing the lowest order set of interaction parameters that it does estimate. 


\section{Yates' Order of Treatment Combinations}

General rules enabling the use of Yates' algorithm with the observations resulting from telescoping sequences of experiments are given in reference 1 . The rules in the present discussion are more narrowly stated. The purpose of the narrow statement is to arrive more easily at a list of treatment combinations and parameters that are in Yates' order. Thus, if the responses are listed in Yates' order, then Yates' computational procedure gives estimates that are in the order of easily identified sets of aliased parameters. Actually, the narrowly stated rules result in no loss of generality, because the experimenter is free to assign the symbols $\mathrm{A}, \mathrm{B}, \ldots ., \mathrm{H}$ to the physical variables in any order he chooses.

\section{Treatments and Parameters of the First Block}

The treatment levels for the first block are listed in Yates' order in table IV together with the parameters in Yates' order that are estimated by Yates' algorithm. The method used to obtain Yates' order for the treatments is as follows. The 1/32 replicate contains eight treatments, and the treatments for a full factorial experiment on three factors are first listed in the treatment column. The result is a list, in Yates' order, involving the letters $a, b$, and $c$. (The treatment with all factors at the low level is signified by the (1) in table IV.)

The high levels of the factors $x_{D}, x_{E}, x_{F}, x_{G}$, and $x_{H}$ are to be added to the design according to rules derived from equations (1). Thus, if the contrast $E$ is to equal the contrast $-\mathrm{AC}$, then the high level of $\mathrm{x}_{\mathrm{E}}$ (designated by $\mathrm{e}$ ) is to occur whenever the product of $\mathrm{x}_{\mathrm{A}}$ and $\mathrm{x}_{\mathrm{C}}$ is negative. This occurs in table $\mathrm{IV}$ wherever there is an odd number of the letters a and $\mathrm{c}$. The letter $\mathrm{e}$ was added to the treatments of table IV, accordingly, wherever the number of letters a and $c$ was odd. Equations (1) show that the same rule should be followed for the letter $f$ for the combination $a b$.

Equations (1) show that the high level of $x_{H}$ is to occur whenever the product of the levels of $\mathrm{x}_{\mathrm{A}}, \mathrm{x}_{\mathrm{B}}$, and $\mathrm{x}_{\mathrm{C}}$ is positive. This will occur wherever table IV contains an odd number of the letters $a, b$, and c. Accordingly, the letter $h$ was added to the treatments of table IV at every occurrence of an odd number of the letters $a, b$, and $c$.

The identification of the parameters estimated by Yates' algorithm is as follows. The use of Yates' algorithm for a full factorial experiment on the factors $x_{A}, x_{B}$, and $\mathbf{x}_{C}$ provides estimates (in Yates' order) of the parameters $\beta_{\mathrm{I}}, \beta_{\mathrm{A}}, \beta_{\mathrm{B}}, \beta_{\mathrm{AB}}, \beta_{\mathrm{C}}, \beta_{\mathrm{AC}}$, $\beta_{\mathrm{BC}}$, and $\beta_{\mathrm{ABC}}$. These parameters are therefore estimated when Yates' algorithm is applied to observations listed in the order of the associated treatments of table IV. Because of the fractional replication, these parameters are each aliased with 31 other parameters determinable from the list of defining contrasts of table II. Table IV does not 
contain the entire list of aliased sets of parameters, but only lists the parameters for the main effects and two-factor interactions that occur in the aliased sets.

\section{Treatments and Parameters of Subsequent Blocks}

The rules just illustrated for establishing the treatments and parameter estimates of the first block were also used to establish the treatments and parameter estimates for the subsequent blocks.

The rules for constructing treatment lists in tables V, VI, and VII were obtained from the defining contrasts of table $\Pi$. The defining contrasts show that the following equations apply:

$(1,2)$ experiment:

$$
\begin{aligned}
& \mathbf{E}=-\mathrm{AC} \\
& \mathbf{F}=-\mathrm{AB} \\
& \mathbf{G}=\mathrm{BCD} \\
& \mathbf{H}=\mathrm{ACD}
\end{aligned}
$$

$(1,4)$ experiment:

$$
\begin{gathered}
F=B C E \\
G=-A B D E \\
H=A C D
\end{gathered}
$$

$(1,8)$ experiment:

$$
\begin{aligned}
& \mathrm{G}=-\mathrm{ABDE} \\
& \mathrm{H}=\mathrm{ABDEF}
\end{aligned}
$$

Rules for the construction of the treatment lists and for the identification of the aliased parameters were just illustrated for the 1/32 replicate of table IV. The same rules were used for the construction of treatment lists and for the identification of ali- 
ased parameters in tables $\mathrm{V}$ to $\mathrm{XI}$.

The assignment of treatments to the first block was performed as indicated in the discussion of the treatment list for table IV. The assignment of treatments to blocks in the subsequent tables was done as indicated by figure 1 and in accordance with rules given in reference 7 .

With reference to figure 1 , for the sequence of blocks for $i=1$ and running from $\mathrm{j}=1,2, \ldots ., 8$, each new block represents a new condition within the reactor cycle and therefore a new block mean. In this situation, the number of parameter estimates (as computed, for example, by the Yates' procedure) that are confounded with block differences is always one less than the number of blocks. Furthermore, when the estimation is being done for a regular fractional replicate consisting of rc blocks, then where $\mathrm{C}(\mathrm{r}, \mathrm{c})$ is the group of defining contrasts for the rc blocks the defining contrasts that are contained in $\mathrm{C}(\mathrm{r}, 1)$ but not in $\mathrm{C}(\mathrm{r}, \mathrm{c})$ identify the parameter estimates confounded with column block differences. Such parameters are identified by the superscript $c$ in tables $\mathrm{V}$ to XI. The contrasts contained in $\mathrm{C}(1, \mathrm{c})$ and not in $\mathrm{C}(\mathrm{r}, \mathrm{c})$ identify the parameters confounded with row block effects, and such parameters are identified by the superscript $r$ in tables $\mathrm{V}$ to $\mathrm{XI}$.

The assumption about the block effect that changes during the performance of a reactor cycle is that it repeats during subsequent reactor cycles. Also, the change that is assumed to occur between one block of reactor cycles and another is assumed to remain constant throughout the cycles. Thus, in figure 1, the column to column changes are assumed to be the same for the two rows and the differences between rows are assumed to be the same in any column. In this situation the rows and columns have been assumed to be noninteracting, and the two sources of block effects are said to be additive with respect to each other. Correspondingly, the number of aliased sets of parameters having estimates confounded with the column block effects is $c-1$, and the number of aliased sets of parameters having estimates confounded with row block effects is $\mathbf{r}-1$.

In the first case of blocking on rows (table VIII), the estimates confounded with the row differences are identified by the elements of $C(1,1)$ not contained in the group $\mathrm{C}(2,1)$ of table III. The aliased sets of coefficients include orders up to only the two factor interactions in table VIII. The confounded estimate is the one labeled $\left(\beta_{\mathrm{BD}}+\beta_{\mathrm{CG}}\right)$.

The next step of the crossed blocking is shown by table IX. Parameter estimates of table IX that are confounded with the row and column differences are to be identified. Because the table lists no coefficients higher than three factor interactions, only defining contrasts containing three letters or less need be considered. Such coefficient estimates as are confounded with differences between the two columns are given by the elements of $\mathrm{C}(2,1)$ that are not contained in $\mathrm{C}(2,2)$ - namely, -AEG and -CFH (see table III). The parameters of table IX confounded with the row differences are identified by the elements of $\mathrm{C}(1,2)$ that do not appear in $\mathrm{C}(2,2)$. The three letter words are -ACE and $-\mathrm{FGH}$, 
and, thus, the estimate confounded with row differences is identified as $\left(\beta_{\mathrm{ACE}}+\beta_{\mathrm{FGH}}\right)$ in table IX.

The $(2,4)$ experiment is described in table $\mathrm{X}$. The parameter estimates in it that are confounded with row differences are identified by the elements of $C(1,4)$ that do not occur in $C(2,4)$. As may be seen from tables $I I$ and $I I$, the contrasts are ACDH, BCEF, -ABDEG, and -FGH. Because table X only lists parameters of third order or lower, the only estimate of table $\mathrm{X}$ that is confounded with the row block effect is the estimate of $-\beta_{\text {FGH }}$. With respect to column blocking, the telescoping from $\mathrm{C}(2,2)$ to $\mathrm{C}(2,4)$ involves going from two to four columns and a total of three estimates are confounded with column differences. These estimates are identified by the defining contrasts for the first column (namely $\mathrm{C}(2,1)$ ) that are not contained in $\mathrm{C}(2,4)$. From table III the contrasts are $-\mathrm{ABF},-\mathrm{AEG},-\mathrm{CFH},-\mathrm{DEH}$, and, as listed in table $\mathrm{X}$, the associated estimates are $\beta_{\mathrm{CFH}},\left(\beta_{\mathrm{ABF}}+\beta_{\mathrm{DEH}}\right)$, and $\beta_{\mathrm{AEG}}$.

The $(2,8)$ experiment is described in table XI. The parameter estimates in it that are confounded with row differences are identified by the elements of $C(1,8)$ not contained in $\mathrm{C}(2,8)$. From table II, these elements are -ABDEG and -FGH, and, because the $(2,8)$ experiment has defining contrasts $I=A B D E F H$, the rows are confounded with the aliased pair $\beta_{\mathrm{ABDEG}}+\beta_{\mathrm{FGH}}$ of which only the third order coefficient is listed in table XI. The $(2,8)$ experiment contains 8 columns and therefore $8-1=7$ of the estimates of table XI are confounded with column differences. These estimates are identified by the defining contrasts of $\mathrm{C}(2,1)$ (in table III) not contained in the group $I=A B D E F H$. The corresponding lower order members of the parameter pairs aliased through $I=A B D E F H$ are designated by the superscript $c$ of table XI.

\section{Summary of the Properties of the Design}

The detailed arrangement of the assignment of treatments to blocks is shown in table XII. In table XII the confounding of the fluid variables with column block effects is shown by listing the fluid variable treatments under the column headings consisting of the block numbers. The confounding of the mechanical variables between the two rows of blocks is exhibited in table XII by the listing of the mechanical treatments (1), fg, fh, and gh for the first row of blocks followed by the listing of the treatments $f, g, h$, and fgh for the second row.

The details of where in the sequences of telescoping designs each parameter first becomes estimable are given in table XIII. (A parameter is estimable if its estimate does not include an alias with a parameter of the same or lower order.) Only parameters up to the three factor interactions have been listed in table XIII. The numbers in the columns opposite each parameter give the number of completed blocks at which the parameter first becomes estimable for the type of telescoping indicated by the column 
heading. The superscript $c$ or $\mathbf{r}$ over a number of blocks means that at that stage of completion of the blocks, the parameter is confounded with column or row block effects, respectively, and as such only represents a true response to treatment variables if the experimenter has prior knowledge that the respective block effect is negligible.

Some properties of the design as evidenced in table XIII are summarized in table XIV. It gives the number of two and three factor interactions that occur in a full factorial experiment on eight factors together with the numbers of these interactions that are estimable at various stages of completion of the blocks.

\section{Assignment of Symbols to Variables}

The experimenter might be fortunate enough to have some prior knowledge of the tendency of the variables to interact. Such knowledge can be used to protect against the hazard that all the blocks might not be completed. The protection requires a judicious assignment of the symbols $A, B, C, D, E, F, G$, and $H$ to the physical variables. Of course, as specified earlier, the symbols F, G, and $\mathrm{H}$ can be assigned only to the mechanical variables and the symbols $A, B, C, D$, and $E$ can be used only for the fluid variables.

\section{CONCLUDING REMARKS}

The problem considered was that of designing an experiment for use in the presence of two types of block effects where unplanned curtailments of the experimenting might take place with respect to one type of block effect and where expansions of the originally planned experiment might be desirable with respect to the second. The use of an indefinite number of blocks can result in parameter estimates that are biased by the block effects unless special precautions are taken. Such precautions were described under the name of "telescoping sequences of designs." The rules for constructing telescoping sequences were justified using some basic ideas of group theory. Use of the rules was illustrated by the generation of a sequence of designs intended for a radiation experiment to be performed in a nuclear reactor.

The specific problem involved a class of independent variables whose levels are easily changed (fluid variables) and a class of independent variables whose levels are not easily changed (mechanical variables). Economy of experimentation suggests that many combinations of levels (treatments) of the fluid variables be performed for each treatment of the mechanical variables. The differing treatments of the fluid variables are assumed to be accompanied by time effects and the performance of blocks of the treatments of the mechanical variables might be confounded with equipment or instrument changes. 
The experiment is to be designed as a doubly telescoping sequence of blocks so that even if for many of the treatments of the mechanical variables the experimenting is stopped short of completion of all the treatments of the fluid variables, the more important parameters will be estimated without large biases being introduced because of the missing data. If additional treatments of the mechanical variables are desired, a new block of mechanical variable treatments may be added so that the resulting block effect will be confounded with only the highest order (three factor) interaction among the mechanical variables.

The treatments of the fluid variables are assigned to eight time blocks of the reactor cycle. The telescoping is such that completion of $2,4,8$, or 16 of the blocks results in a fractional replicate experiment of size $2 / 32,4 / 32,8 / 32$, or $16 / 32$, respectively.

Completion of the first two blocks provides estimates of all of the main effects. Completion of four blocks provides estimates of about one-half of the two-factor interactions. Completion of eight blocks provides estimates of almost all of the two factor interactions, and completion of sixteen blocks provides estimates of about two-thirds of the three-factor interactions.

Lewis Research Center

National Aeronautics and Space Administration, Cleveland, Ohio, April 24, 1969,

122-29-05-12-22.

\section{REFERENCES}

1. Daniel, Cuthbert: Fractional Replication in Industrial Research. Proceedings of the Third Berkeley Symposium on Mathematical Statistics and Probability. Vol. 5. University of California Press, 1956, pp. 87-98.

2. Webb, Steve R. : Design, Testing and Estimating in Complex Experimentation. 1: Expansible and Contractible Factorial Designs and the Application of Linear Programming to Combinatorial Problems. Rep. R-6078-1 Rocketdyne Div., North American Aviation (ARL-65-116, Pt. I, DDC No. AD-618515), June 1965.

3. John, Peter W. M.: Nested Fractions of $2^{\mathrm{n}}$ Designs. Paper presented at the 35th session of the International Statistical Institute, Belgrade, 1965.

4. Addelman, Sidney: The Selection of Sequences of Two-Level Fractional Factorial Plans. Research Triangle Inst. (ARL-67-0013, DDC No. AD-651806), Jan. 1967.

5. Addelman, Sidney: Research in Sequential Factorial Designs. Research Triangle Inst. (ARL-67-0141, DDC No. AD-660570), July 1967. 
6. Holms, Arthur G.: Designs of Experiments as Telescoping Sequences of Blocks for Optimum Seeking (As Intended for Alloy Development). NASA TN D-4100, 1967.

7. Davies, Owen L., ed.: The Design and Analysis of Industrial Experiments. Second ed., Hafner Publishing Co., 1960.

8. Box, G. E. P.; and Hunter, J. S.: The $2^{\mathrm{k}-\mathrm{p}}$ Fractional Factorial Designs. I. Technometrics, vol. 3, no. 3, Aug. 1961, pp. 311-351.

9. Daniel, Cuthbert; and Wilcoxon, Frank: Factorial $2^{\mathrm{p}-\mathrm{q}}$ Plans Robust Against Linear and Quadratic Trends. Technometrics, vol. 8, no. 2, May 1966, pp. 259-278.

10. Draper, Norman R.; and Stoneman, David M.: Factor Changes and Linear Trends in Eight-Run Two-Level Factorial Designs. Technometrics, vol. 10, no. 2, May 1968, pp. 301-311.

11. Finney, D. J.: The Fractional Replication of Factorial Arrangements. Ann. Eugenics, vol. 12, 1945, pp. 291-301. 
TABLE I. - FULL $2^{4}$ EXPERIMENT

\begin{tabular}{|c|c|c|c|c|c|c|c|c|c|c|c|c|c|c|c|c|c|}
\hline \multirow{2}{*}{$\begin{array}{l}\text { Treat- } \\
\text { ment }\end{array}$} & \multirow[t]{2}{*}{ Response } & \multicolumn{16}{|c|}{ Matrix of independent variables } \\
\hline & & $\mathrm{I}$ & $\mathbf{A}$ & $\mathbf{B}$ & $\mathrm{AB}$ & $\mathbf{C}$ & $\mathrm{AC}$ & $\mathrm{BC}$ & $\mathrm{ABC}$ & $\mathbf{D}$ & $\mathrm{AD}$ & $\mathrm{BD}$ & ABD & $\mathrm{CD}$ & $\mathrm{ACD}$ & $B C D$ & $A B C D$ \\
\hline (1) & $\mathrm{y}_{1}$ & +1 & -1 & -1 & +1 & $-1 \mid$ & +1 & +1 & -1 & -1 & +1 & +1 & -1 & +1 & -1 & -1 & +1 \\
\hline a & $\mathrm{y}_{2}$ & +1 & +1 & -1 & -1 & -1 & -1 & +1 & +1 & -1 & -1 & +1 & +1 & +1 & +1 & -1 & -1 \\
\hline $\mathrm{b}$ & $\mathrm{y}_{3}$ & +1 & -1 & +1 & -1 & -1 & $+\mathbf{1}$ & -1 & +1 & $|-1|$ & +1 & -1 & +1 & +1 & -1 & +1 & -1 \\
\hline$a b$ & $\mathrm{y}_{4}$ & +1 & +1 & +1 & +1 & -1 & -1 & -1 & -1 & $|-1|$ & -1 & -1 & -1 & +1 & +1 & +1 & +1 \\
\hline $\mathrm{c}$ & $\mathrm{y}_{5}$ & +1 & -1 & -1 & +1 & +1 & -1 & -1 & +1 & $|-1|$ & +1 & +1 & -1 & -1 & +1 & +1 & -1 \\
\hline $\mathrm{ac}$ & $\mathrm{y}_{6}$ & +1 & +1 & -1 & -1 & +1 & +1 & -1 & -1 & $|-1|$ & -1 & +1 & +1 & -1 & -1 & +1 & +1 \\
\hline bc & $y_{7}$ & +1 & -1 & +1 & -1 & +1 & -1 & +1 & -1 & $|-1|$ & +1 & -1 & +1 & -1 & +1 & -1 & +1 \\
\hline$a b c$ & $\mathrm{y}_{8}$ & +1 & +1 & +1 & +1 & +1 & $+\mathbf{1}$ & +1 & +1 & $|-1|$ & -1 & -1 & -1 & -1 & -1 & -1 & -1 \\
\hline$d$ & $y_{9}$ & +1 & -1 & -1 & +1 & $-1 \mid$ & +1 & +1 & -1 & +1 & -1 & -1 & +1 & -1 & +1 & +1 & -1 \\
\hline $\mathrm{ad}$ & $\mathrm{y}_{10}$ & +1 & +1 & -1 & -1 & $-1 \mid$ & -1 & +1 & +1 & +1 & +1 & -1 & -1 & -1 & -1 & +1 & +1 \\
\hline bd & $\mathrm{y}_{11}$ & +1 & -1 & +1 & -1 & -1 & +1 & -1 & +1 & +1 & -1 & +1 & -1 & -1 & +1 & -1 & +1 \\
\hline abd & $\mathrm{y}_{12}$ & +1 & +1 & +1 & +1 & -1 & -1 & -1 & -1 & +1 & +1 & +1 & +1 & -1 & -1 & -1 & -1 \\
\hline $\mathrm{cd}$ & $\mathrm{y}_{13}$ & +1 & -1 & -1 & +1 & +1 & -1 & -1 & +1 & +1 & -1 & -1 & +1 & +1 & -1 & -1 & +1 \\
\hline acd & $\mathrm{y}_{14}$ & +1 & +1 & -1 & -1 & +1 & +1 & -1 & -1 & +1 & +1 & -1 & -1 & +1 & +1 & -1 & -1 \\
\hline bcd & $\mathrm{y}_{15}$ & +1 & -1 & +1 & -1 & +1 & -1 & +1 & -1 & +1 & -1 & +1 & -1 & +1 & -1 & +1 & -1 \\
\hline abcd & $\mathrm{y}_{16}$ & +1 & +1 & +1 & +1 & $+1 \mid$ & +1 & +1 & +1 & +1 & +1 & +1 & +1 & +1 & +1 & +1 & +1 \\
\hline
\end{tabular}


TABLE II. - DEFINING CONTRASTS, FIRST ROW OF BLOCKS

\begin{tabular}{|c|c|c|c|c|c|c|c|}
\hline \multicolumn{2}{|c|}{$(1,1)$ Replicate } & \multicolumn{2}{|c|}{$(1,2)$ Replicate } & \multicolumn{2}{|c|}{$(1,4)$ Replicate } & \multicolumn{2}{|c|}{$(1,8)$ Replicate } \\
\hline & I & & I & & I & & I \\
\hline B & D & & & & & & \\
\hline$-A C$ & $\mathbf{E}$ & $-A C$ & $\mathbf{E}$ & & & & \\
\hline$-\mathrm{AB}$ & $\mathbf{F}$ & $-\mathrm{AE}$ & $\mathbf{F}$ & & & & \\
\hline $\mathrm{C}$ & G & & & & & & \\
\hline $\mathrm{ABC}$ & $\mathrm{H}$ & & & & & & \\
\hline$-A B C$ & $\mathrm{DE}$ & & & & & & \\
\hline$-A$ & $\mathrm{DF}$ & & & & & & \\
\hline $\mathrm{BC}$ & DG & $\mathrm{BCD}$ & G & & & & \\
\hline AC & $\mathrm{DH}$ & $\mathrm{ACD}$ & $\mathrm{H}$ & $\mathrm{ACD}$ & & & \\
\hline $\mathrm{BC}$ & EF & $\mathrm{BC}$ & EF & $\mathrm{BCE}$ & & & \\
\hline$-A$ & $\mathrm{EG}$ & & & & & & \\
\hline$-\mathrm{B}$ & EH & & & & & & \\
\hline$-A B C$ & FG & & & & & & \\
\hline$-\mathrm{C}$ & FH & & & & & & \\
\hline$A B$ & GH & $\mathrm{AB}$ & GH & & & & \\
\hline $\mathrm{C}$ & $\mathrm{DEF}$ & & & & & & \\
\hline$-A B$ & DEG & $-A B D$ & EG & -ABDE & G & $-A B D E$ & G \\
\hline - & DEH & $-D$ & $\mathrm{EH}$ & & & & \\
\hline$-A C$ & DFG & $-A C D$ & $\mathrm{FG}$ & $-A C D$ & $F G$ & & \\
\hline$-B C$ & $\mathrm{DFH}$ & $-B C D$ & $\mathrm{FH}$ & & & & \\
\hline A & DGH & & & & & & \\
\hline $\mathrm{B}$ & EFG & & & & & & \\
\hline A & $\mathrm{EFH}$ & & & & & & \\
\hline$-B C$ & $\mathrm{EGH}$ & $-B C$ & $\mathrm{EGH}$ & $-B C E$ & GH & & \\
\hline - & $\mathrm{FGH}$ & - & FGH & - & $\mathrm{FGH}$ & $-F$ & $\mathrm{GH}$ \\
\hline & DEFG & D & $E F G$ & & & & \\
\hline$A B$ & DEFH & $A B D$ & $\mathrm{EFH}$ & ABDE & FH & ABDEF & $\mathrm{H}$ \\
\hline$-\mathrm{C}$ & DEGH & & & & & & \\
\hline$-B$ & DFGH & & & & & & \\
\hline $\mathrm{AC}$ & EFGH & $\mathrm{AC}$ & EFGH & & & & \\
\hline $\mathrm{ABC}$ & DEFGH & & & & & & \\
\hline
\end{tabular}


TABLE III. - DEFINING CONTRASTS, TWO ROWS OF BLOCKS

\begin{tabular}{|c|c|c|c|c|c|c|c|}
\hline$(1,1)$ & Replicate & $(2,1) R e$ & plicate & $(2,2) \mathrm{Re}$ & plicate & $(2,4)$ Repli & cate \\
\hline & I & & I & & I & & I \\
\hline B & D & & & & & & \\
\hline$-A C$ & $\mathrm{E}$ & & & & & & \\
\hline$-A B$ & $\mathbf{F}$ & $-A B$ & $\mathbf{F}$ & $-A B$ & $\mathbf{F}$ & & \\
\hline $\mathrm{C}$ & $\mathrm{G}$ & & & & & & \\
\hline$A B C$ & $\mathrm{H}$ & $A B C$ & $\mathrm{H}$ & & & & \\
\hline$-A B C$ & $\mathrm{DE}$ & -ABCD & $\mathbf{E}$ & & & & \\
\hline$-A$ & DF & & & & & & \\
\hline $\mathrm{BC}$ & DG & BCD & G & $\mathrm{BCD}$ & G & & \\
\hline $\mathrm{AC}$ & $\mathrm{DH}$ & & & & & & \\
\hline BC & EF & & & & & & \\
\hline$-A$ & EG & $-A$ & EG & & & & \\
\hline$-B$ & $\mathrm{EH}$ & & & & & & \\
\hline$-A B C$ & FG & & & & & & \\
\hline$-C$ & FH & $-\mathrm{C}$ & FH & & & & \\
\hline $\mathrm{AB}$ & $\mathrm{GH}$ & & & & & & \\
\hline $\mathrm{C}$ & $\mathrm{DEF}$ & CD & EF & & & & \\
\hline$-A B$ & $\mathrm{DEG}$ & & & & & & \\
\hline - & $\mathrm{DEH}$ & $-D$ & EH & $-\mathrm{DE}$ & H & & \\
\hline$-A C$ & $\mathrm{DFG}$ & $-A C D$ & FG & $-A C D$ & FG & -ACDF & G \\
\hline$-B C$ & DFH & & & & & & \\
\hline A & DGH & $\mathrm{AD}$ & GH & & & & \\
\hline B & $\mathrm{EFG}$ & B & EFG & & & & \\
\hline A & $\mathrm{EFH}$ & & & & & & \\
\hline$-B C$ & EGH & $-B C$ & EGH & $-B C E$ & GH & $-B C E$ & GH \\
\hline - & $\mathrm{FGH}$ & & & & & & \\
\hline & DEFG & & & & & & \\
\hline$A B$ & DEFH & ABD & EFH & $\mathrm{ABDE}$ & $\mathrm{FH}$ & ABDEF & $\mathrm{H}$ \\
\hline$-C$ & $\mathrm{DEGH}$ & & & & & & \\
\hline$-B$ & DFGH & $-B D$ & FGH & & & & \\
\hline AC & EFGH & AC & EFGH & $\mathrm{ACE}$ & FGH & & \\
\hline $\mathrm{ABC}$ & DEFGH & & & & & & \\
\hline
\end{tabular}


TABLE IV. - (1, 1) REPLICATE

[Defining contrasts given by table $\Pi$.]

\begin{tabular}{|c|c|}
\hline Block & Treatment \\
\hline 1 & $(1)$ \\
1 & aefh \\
1 & bdfh \\
1 & abde \\
1 & cegh \\
1 & acfg \\
1 & bcdefg \\
1 & abcdgh \\
\hline
\end{tabular}

Estimate

$$
\beta_{\mathrm{I}}+\beta_{\mathrm{BD}}+\beta_{\mathrm{CG}}
$$

$\beta_{\mathrm{A}}-\beta_{\mathrm{CE}}-\beta_{\mathrm{DF}}-\beta_{\mathrm{EG}}-\beta_{\mathrm{BF}}$

$\beta_{\mathrm{B}}+\beta_{\mathrm{D}}-\beta_{\mathrm{EH}}-\beta_{\mathrm{AF}}$

$\beta_{\mathrm{AB}}-\beta_{\mathrm{F}}+\beta_{\mathrm{CH}}+\beta_{\mathrm{GH}}+\beta_{\mathrm{AD}}$

$\beta_{\mathrm{C}}+\beta_{\mathrm{G}}-\beta_{\mathrm{FH}}-\beta_{\mathrm{AE}}$

$\beta_{\mathrm{AC}}-\beta_{\mathrm{E}}+\beta_{\mathrm{BH}}+\beta_{\mathrm{DH}}+\beta_{\mathrm{AG}}$

$\beta_{\mathrm{BC}}+\beta_{\mathrm{AH}}+\beta_{\mathrm{DG}}+\beta_{\mathrm{EF}}+\beta_{\mathrm{CD}}+\beta_{\mathrm{BG}}$

$\beta_{\mathrm{H}}-\beta_{\mathrm{DE}}-\beta_{\mathrm{FG}}-\beta_{\mathrm{BE}}-\beta_{\mathrm{CF}}$

\section{TABLE V. - (1,2) REPLICATE}

[Defining contrasts given by table II; estimates confounded with column block differences have superscript c.]

\begin{tabular}{|c|c|c|}
\hline Block & Treatment & Estimate \\
\hline 1 & (1) & $\beta_{\mathrm{I}}$ \\
\hline 1 & aefh & $\beta_{\mathrm{A}}-\beta_{\mathrm{CE}}-\beta_{\mathrm{BF}}$ \\
\hline 2 & bfg & $\beta_{\mathrm{B}}-\beta_{\mathrm{AF}}$ \\
\hline 2 & abegh & $\beta_{\mathrm{AB}}-\beta_{\mathrm{F}}+\beta_{\mathrm{GH}}$ \\
\hline 1 & cegh & $\beta_{\mathrm{C}}-\beta_{\mathrm{AE}}$ \\
\hline 1 & acfg & $\beta_{\mathrm{AC}}-\beta_{\mathrm{E}}+\beta_{\mathrm{DH}}$ \\
\hline 2 & bcefh & $\beta_{\mathrm{BC}}+\beta_{\mathrm{EF}}+\beta_{\mathrm{DG}}$ \\
\hline 2 & $a b c$ & $-\beta_{\mathrm{BE}}-\beta_{\mathrm{CF}}$ \\
\hline 2 & dgh & $\beta_{\mathrm{D}}-\beta_{\mathrm{EH}}$ \\
\hline 2 & adefg & $\beta_{\mathrm{AD}}+\beta_{\mathrm{CH}}$ \\
\hline 1 & bdfh & $\left(\beta_{\mathrm{BD}}+\beta_{\mathrm{CG}}\right)^{\mathrm{c}}$ \\
\hline 1 & abde & ${ }^{-\beta} \mathrm{DF}-\beta_{\mathrm{EG}}$ \\
\hline 2 & cde & $\beta_{\mathrm{CD}}+\beta_{\mathrm{BG}}+\beta_{\mathrm{AH}}$ \\
\hline 2 & acdfh & $\beta_{\mathrm{H}}-\beta_{\mathrm{FG}}-\beta_{\mathrm{DE}}$ \\
\hline 1 & bcdefg & $\beta_{\mathrm{G}}-\beta_{\mathrm{FH}}$ \\
\hline 1 & abcdgh & $\beta_{\mathrm{AG}}+\beta_{\mathrm{BH}}$ \\
\hline
\end{tabular}


TABLE VI. - $(\mathbf{1}, 4)$ REPLICATE

$[\mathrm{I}=\mathrm{ACDH}=\mathrm{BCEF}=-\mathrm{ABDEG}=-\mathrm{ACDFG}=-\mathrm{BCEGH}=-\mathrm{FGH}=\mathrm{ABDEFH}$; estimates confounded with column block differences have superscript c.]

\begin{tabular}{|c|c|c|c|c|c|}
\hline Block & Treatment & Estimate & Block & Treatment & Estimate \\
\hline 1 & (1) & $\beta_{\mathbf{I}}-\beta_{\mathbf{F G H}}$ & 3 & efg & $\beta_{E}+\beta_{B C F}$ \\
\hline 3 & agh & ${ }^{\beta} \mathbf{A}+\beta_{\mathrm{CDH}}$ & 1 & aefh & $\beta_{\mathrm{AE}}-\beta_{\mathrm{BDG}}$ \\
\hline 2 & bfg & ${ }^{\beta} \mathbf{B}+\beta_{\mathbf{C E F}}$ & 4 & be & $\beta_{\mathrm{BE}}+\beta_{\mathrm{CF}}-\beta_{\mathrm{ADG}}-\beta_{\mathrm{CGH}}$ \\
\hline 4 & abfh & $\beta_{A B}-\beta_{D E G}$ & 2 & abegh & $\beta_{\mathrm{ABE}}-\beta_{\mathrm{DG}}+\beta_{\mathrm{ACF}}+\beta_{\mathrm{DFH}}$ \\
\hline 3 & $\operatorname{cfh}$ & $\beta_{\mathrm{C}}+\beta_{\mathrm{ADH}}+\beta_{\mathrm{BEF}}$ & 1 & cegh & $\beta_{\mathrm{CE}}+\beta_{\mathrm{BF}}-\beta_{\mathrm{BGH}}$ \\
\hline 1 & acfg & $\beta_{\mathrm{AC}}+\beta_{\mathrm{DH}}-\beta_{\mathrm{DFG}}$ & 3 & ace & $\left(\beta_{\mathrm{ACE}}+\beta_{\mathrm{DEH}}+\beta_{\mathrm{ABF}}\right)^{\mathrm{c}}$ \\
\hline 4 & begh & $\beta_{\mathrm{BC}}+\beta_{\mathrm{EF}}-\beta_{\mathrm{EGH}}$ & 2 & bcefh & $\beta_{\mathrm{BCE}}+\beta_{\mathrm{F}}-\beta_{\mathrm{GH}}$ \\
\hline 2 & $a b c$ & $\beta_{\mathrm{ABC}}+\beta_{\mathrm{BDH}}+\beta_{\mathrm{AEF}}$ & 4 & abcefg & $\beta_{\mathrm{AF}}-\beta_{\mathrm{CDG}}-\beta_{\mathrm{AGH}}$ \\
\hline 2 & $\operatorname{dgh}$ & $\beta_{\mathrm{D}}+\beta_{\mathrm{ACH}}$ & 4 & defh & $\beta_{\mathrm{DE}}-\beta_{\mathrm{ABG}}$ \\
\hline 4 & $\mathrm{ad}$ & $\beta_{\mathrm{AD}}+\beta_{\mathrm{CH}}-\beta_{\mathrm{BEG}}-\beta_{\mathrm{CFG}}$ & 2 & adefg & $\beta_{\mathrm{ADE}}-\beta_{\mathrm{BG}}+\beta_{\mathrm{BFH}}+\beta_{\mathrm{CEH}}$ \\
\hline 1 & bdfh & $\left(\beta_{\mathrm{BD}}-\beta_{\mathrm{AEG}}\right)^{\mathrm{c}}$ & 3 & bdegh & $\beta_{\mathrm{BDE}}-\beta_{\mathrm{AG}}+\beta_{\mathrm{AFH}}+\beta_{\mathrm{CDF}}$ \\
\hline 3 & abdfg & $\beta_{\mathrm{ABD}}+\beta_{\mathrm{BCH}}-\beta_{\mathrm{EG}}+\beta_{\mathrm{EFH}}$ & 1 & abde & $-\beta_{\mathrm{G}}+\beta_{\mathrm{FH}}$ \\
\hline 4 & $\operatorname{cdfg}$ & ${ }^{\beta} \mathrm{CD}^{+\beta_{\mathrm{AH}}-\beta_{\mathrm{AFG}}}$ & 2 & cde & $\beta_{\mathrm{CDE}}+\beta_{\mathrm{AEH}}+\beta_{\mathrm{BDF}}$ \\
\hline 2 & acdfh & $\beta_{\mathrm{ACD}}+\beta_{\mathrm{H}}-\beta_{\mathrm{FG}}$ & 4 & acdegh & $\beta_{\mathrm{EH}}-\beta_{\mathrm{EFG}}-\beta_{\mathrm{BCG}}$ \\
\hline 3 & bed & $\beta_{\mathrm{BCD}}+\beta_{\mathrm{ABH}}+\beta_{\mathrm{DEF}}$ & 1 & bcdefg & $\beta_{\mathrm{DF}}-\beta_{\mathrm{ACG}}-\beta_{\mathrm{DGH}}$ \\
\hline 1 & abcdgh & $\beta_{\mathrm{BH}}-\beta_{\mathrm{CEG}}-\beta_{\mathrm{BFG}}$ & 3 & abcdefh & $\left(\beta_{\mathrm{CG}}-\beta_{\mathrm{ADF}}-\beta_{\mathrm{BEH}}-\beta_{\mathrm{CFH}}\right)^{c}$ \\
\hline
\end{tabular}


TABLE VII. - $(1,8)$ REPLICATE

$[\mathrm{I}=-\mathrm{ABDEG}=-\mathrm{FGH}=\mathrm{ABDEFH} ;$ estimates confounded with column block differences have superscript $c$.

\begin{tabular}{|c|c|c|c|c|c|c|c|c|c|c|c|}
\hline Block & $\begin{array}{c}\text { Treat- } \\
\text { ment }\end{array}$ & Estimate & Block & $\begin{array}{c}\text { Treat- } \\
\text { ment }\end{array}$ & Estimate & Block & $\begin{array}{c}\text { Treat- } \\
\text { ment }\end{array}$ & Estimate & Block & $\begin{array}{c}\text { Treat- } \\
\text { ment }\end{array}$ & Estimate \\
\hline 1 & (1) & $\beta_{\mathbf{I}}-\beta_{F G H}$ & 7 & egh & $\beta_{\mathrm{E}}$ & 8 & fh & $\beta_{\mathrm{F}}-\beta_{\mathrm{GH}}$ & 3 & efg & $\beta_{\mathbf{E F}}-\beta_{\mathrm{EGH}}$ \\
\hline 3 & agh & $\beta_{\mathrm{A}}$ & 8 & ae & $\beta_{\mathrm{AE}}-\beta_{\mathrm{BDG}}$ & 7 & afg & ${ }^{\beta} \mathrm{AF}^{-\beta_{\mathrm{AGH}}}$ & 1 & aefh & $\beta_{\mathrm{AEF}}+\beta_{\mathrm{BDH}}$ \\
\hline 5 & bgh & $\beta_{\mathrm{B}}$ & 4 & be & $\beta_{\mathrm{BE}}-\beta_{\mathrm{ADG}}$ & 2 & bfg & $\beta_{\mathrm{BF}}-\beta_{\mathrm{BGH}}$ & 6 & befh & $\beta_{\mathrm{BEF}}+\beta_{\mathrm{ADH}}$ \\
\hline 6 & $a b$ & $\beta_{\mathrm{AB}}-\beta_{\mathrm{DEG}}$ & 2 & abegh & $\beta_{\mathrm{ABE}}+\beta_{\mathrm{DFH}}-\beta_{\mathrm{DG}}$ & 4 & abfh & $\left(\beta_{\mathrm{ABF}}+\beta_{\mathrm{DEH}}\right)^{\mathrm{c}}$ & 5 & abefg & $\beta_{\mathrm{DH}}-\beta_{\mathrm{DFG}}$ \\
\hline 7 & c & $\beta_{\mathrm{C}}$ & 1 & cegh & ${ }^{\beta} \mathrm{CE}$ & 3 & efh & ${ }^{\beta} \mathrm{CF}^{-{ }^{\beta} \mathrm{CGH}}$ & 8 & cefg & $\beta_{\mathrm{CEF}}$ \\
\hline 8 & acgh & $\beta_{\mathrm{AC}}$ & 3 & ace & $\left(\beta_{\mathrm{ACE}}\right)^{\mathrm{c}}$ & 1 & acfg & ${ }^{\beta} \mathrm{ACF}$ & 7 & acefh & $\beta_{\mathrm{ACEF}}+\beta_{\mathrm{BCDH}}$ \\
\hline 4 & begh & $\beta_{\mathrm{BC}}$ & 5 & bce & $\beta_{\mathrm{BCE}}$ & 6 & befg & $\beta_{\mathrm{BCF}}$ & 2 & bcefh & $\left(\beta_{\mathrm{BCEF}}+\beta_{\mathrm{ACDH}}\right)^{\mathrm{c}}$ \\
\hline 2 & $a b c$ & ${ }^{\beta} \mathrm{ABC}$ & 6 & abcegh & ${ }^{-\beta} \mathrm{CDG}$ & 5 & abcth & $\beta_{\mathrm{ABCF}}+\beta_{\mathrm{CDEH}}$ & 4 & abcefg & ${ }^{\beta} \mathrm{CDH}$ \\
\hline 2 & dgh & $\beta_{\mathrm{D}}$ & 6 & de & $\beta_{\mathrm{DE}}-\beta_{\mathrm{ABG}}$ & 5 & dfg & $\beta_{\mathrm{DF}}-\beta_{\mathrm{DGH}}$ & 4 & defh & ${ }^{\beta}{ }_{\mathrm{DEF}}+\beta_{\mathrm{ABH}}$ \\
\hline 4 & ad & $\beta_{\mathrm{AD}}-\beta_{\mathrm{BEG}}$ & 5 & adegh & $\beta_{\mathrm{ADE}}+\beta_{\mathrm{BFH}}-\beta_{\mathrm{BG}}$ & 6 & adfh & $\left(\beta_{\mathrm{ADF}}+\beta_{\mathrm{BEH}}\right)^{\mathrm{c}}$ & 2 & adefg & $\beta_{\mathrm{BH}}-\beta_{\mathrm{BFG}}$ \\
\hline 8 & $b d$ & $\left(\beta_{\mathrm{BD}}-\beta_{\mathrm{AEG}}\right)^{\mathrm{c}}$ & 3 & bdegh & $\beta_{\mathrm{BDE}}+\beta_{\mathrm{AFH}}-\beta_{\mathrm{AG}}$ & 1 & bdfh & $\beta_{\mathrm{BDF}}+\beta_{\mathrm{AEH}}$ & 7 & bdefg & $\beta_{\mathrm{AH}}-\beta_{\mathrm{AFG}}$ \\
\hline 7 & abdgh & $\beta_{\mathrm{ABD}}-\beta_{\mathrm{EG}}+\beta_{\mathrm{EFH}}$ & 1 & abde & $-\beta_{\mathrm{G}}+\beta_{\mathrm{FH}}$ & 3 & abdfg & $\beta_{\mathrm{EH}}-\beta_{\mathrm{EFG}}$ & 8 & abdefh & $\beta_{\mathrm{H}}-\beta_{\mathrm{FG}}$ \\
\hline 6 & cdgh & ${ }^{\beta} \mathrm{CD}$ & 2 & cde & ${ }^{\beta} \mathrm{CDE}$ & 4 & cdfg & $\beta_{\mathrm{CDF}}$ & 5 & cdefh & $\left(\beta_{\mathrm{CDEF}}+\beta_{\mathrm{ABCH}}\right)^{c}$ \\
\hline 5 & acd & $\beta_{\mathrm{ACD}}$ & 4 & acdegh & $-\beta_{\mathrm{BCG}}$ & 2 & acdfh & $\beta_{\mathrm{ACDF}}+\beta_{\mathrm{BCEH}}$ & 6 & acdefg & $\beta_{\mathrm{BCH}}$ \\
\hline 3 & $b c d$ & $\beta_{\mathrm{BCD}}$ & 8 & bcdegh & $-\beta_{\mathrm{ACG}}$ & 7 & bcdfh & $\beta_{\mathrm{BCDF}}+\beta_{\mathrm{ACEH}}$ & 1 & bcdefg & ${ }^{\beta} \mathrm{ACH}$ \\
\hline 1 & abcdgh & $-\beta_{\mathrm{CEG}}$ & 7 & abcde & $\left(-\beta_{\mathrm{CG}}+\beta_{\mathrm{CFH}}\right)^{c}$ & 8 & abcdfg & $\beta_{\text {CEH }}$ & 3 & abcdefh & ${ }^{\beta} \mathrm{CH}^{-\beta_{\mathrm{CFG}}}$ \\
\hline
\end{tabular}


TABLE VIII. - $(2,1)$ REPLICATE

[Defining contrasts given by table III; blocking given by fig. 1; estimates confounded with row block differences have superscript $\mathrm{r}$.]

\begin{tabular}{|c|c|c|}
\hline Block & Treatment & Estimate \\
\hline 1 & (1) & $\beta_{\mathrm{I}}$ \\
\hline 1 & aefh & $\beta_{\mathrm{A}}-\beta_{\mathrm{BF}}-\beta_{\mathrm{EG}}$ \\
\hline 9 & befgh & $\beta_{\mathrm{B}}-\beta_{\mathrm{AF}}$ \\
\hline 9 & $\operatorname{abg}$ & $\beta_{\mathrm{AB}}-\beta_{\mathrm{F}}+\beta_{\mathrm{CH}}$ \\
\hline 1 & cegh & $\beta_{C}-\beta_{F H}$ \\
\hline 1 & $\operatorname{acfg}$ & $\beta_{\mathrm{AC}}+\beta_{\mathrm{BH}}$ \\
\hline 9 & bcf & $\beta_{\mathrm{BC}}+\beta_{\mathrm{AH}}+\beta_{\mathrm{DG}}$ \\
\hline 9 & abceh & $-\beta_{\mathrm{CF}}-\beta_{\mathrm{H}}-\beta_{\mathrm{DE}}$ \\
\hline 9 & $\operatorname{deg}$ & $\beta_{\mathrm{D}}-\beta_{\mathrm{EH}}$ \\
\hline 9 & adfgh & $\beta_{\mathrm{AD}}+\beta_{\mathrm{GH}}$ \\
\hline 1 & bdfh & $\left(\beta_{\mathrm{BD}}+\beta_{\mathrm{CG}}\right)^{\mathbf{r}}$ \\
\hline 1 & abde & ${ }^{-\beta_{\mathrm{DF}}}-\beta_{\mathrm{CE}}$ \\
\hline 9 & cdh & $\beta_{\mathrm{CD}}+\beta_{\mathrm{BG}}+\beta_{\mathrm{EF}}$ \\
\hline 9 & acdef & $-\beta_{\mathrm{FG}}-\beta_{\mathrm{BE}}$ \\
\hline 1 & bcdefg & $\beta_{\mathrm{G}}-\beta_{\mathrm{AE}}$ \\
\hline 1 & abcdgh & $\beta_{\mathrm{DH}}-\beta_{\mathrm{E}}+\beta_{\mathrm{AG}}$ \\
\hline
\end{tabular}

TABLE IX. - $(2,2)$ REPLICATE

$[\mathrm{I}=-\mathrm{ABF}=\mathrm{BCDG}=-\mathrm{DEH}=-\mathrm{ACDFG}=-\mathrm{BCEGH}=\mathrm{ABDEFH}=\mathrm{ACEFGH}$; estimates confounded with column block differences have superscript $c$; estimates confounded with row block differences have superscript $r$.

\begin{tabular}{|c|c|c|c|c|c|}
\hline $\begin{array}{l}\text { Block } \\
\text { (a) }\end{array}$ & Treatment & Estimate & $\begin{array}{c}\text { Block } \\
\text { (a) }\end{array}$ & Treatment & Estimate \\
\hline 1 & (1) & $\beta_{\mathrm{I}}-\beta_{\mathrm{ABF}}-\beta_{\mathrm{DEH}}$ & 10 & eh & $\beta_{\mathrm{E}}-\beta_{\mathrm{DH}}$ \\
\hline 10 & af & $\beta_{\mathbf{A}}-\beta_{\mathbf{B F}}$ & 1 & aefh & $\beta_{\mathrm{AE}}-\beta_{\mathrm{ADH}}-\beta_{\mathrm{BEF}}$ \\
\hline 2 & bfg & $\beta_{\mathbf{B}}-\beta_{\mathbf{A F}}+\beta_{\mathrm{CDG}}$ & 9 & befgh & $\beta_{\mathrm{BE}}-\beta_{\mathrm{BDH}}-\beta_{\mathrm{CGH}}-\beta_{\mathrm{AEF}}$ \\
\hline 9 & abg & $\beta_{\mathrm{AB}}-\beta_{\mathbf{F}}$ & 2 & abegh & $\beta_{\mathrm{ABE}}-\beta_{\mathrm{EF}}+\beta_{\mathrm{DFH}}$ \\
\hline 10 & $\mathrm{cg}$ & $\beta_{\mathrm{C}}+\beta_{\mathrm{BDG}}$ & 1 & cegh & $\beta_{\mathrm{CE}}-\beta_{\mathrm{CDH}}-\beta_{\mathrm{BGH}}$ \\
\hline 1 & $\operatorname{acfg}$ & $\beta_{\mathrm{AC}}-\beta_{\mathrm{DFG}}-\beta_{\mathrm{BCF}}$ & 10 & acefgh & $\left(\beta_{\mathrm{ACE}}+\beta_{\mathrm{FGH}}\right)^{\mathrm{r}}$ \\
\hline 9 & bcf & $\beta_{\mathbf{B C}}+\beta_{\mathbf{D G}}-\beta_{\mathbf{E G H}}-\beta_{\mathbf{A C F}}$ & 2 & bcefh & $\beta_{\mathrm{BCE}}+\beta_{\mathrm{DEG}}-\beta_{\mathrm{GH}}$ \\
\hline 2 & $a b c$ & $\beta_{\mathrm{ABC}}-\beta_{\mathrm{CF}}+\beta_{\mathrm{ADG}}$ & 9 & abceh & ${ }^{-\beta} \mathrm{CEF}-\beta_{\mathrm{AGH}}$ \\
\hline 2 & dgh & $\beta_{\mathrm{D}}+\beta_{\mathrm{BCG}}-\beta_{\mathrm{EH}}$ & 9 & deg & $\beta_{\mathrm{DE}}-\beta_{\mathrm{H}}$ \\
\hline 9 & adfgh & $\beta_{\mathrm{AD}}-\beta_{\mathrm{AEH}}-\beta_{\mathrm{CFG}}-\beta_{\mathrm{BDF}}$ & 2 & adefg & $\beta_{\mathrm{ADE}}-\beta_{\mathrm{AH}}-\beta_{\mathrm{BFH}}$ \\
\hline 1 & bdfh & $\beta_{\mathrm{BD}}-\beta_{\mathrm{BEH}}+\beta_{\mathrm{CG}}-\beta_{\mathrm{ADF}}$ & 10 & bdef & $\beta_{\mathrm{BDE}}-\beta_{\mathrm{BH}}+\beta_{\mathrm{AFH}}+\beta_{\mathrm{CEG}}$ \\
\hline 10 & abdh & $\beta_{\mathrm{ABD}}-\beta_{\mathrm{DF}}+\beta_{\mathrm{ACG}}+\beta_{\mathrm{EFH}}$ & 1 & abde & ${ }^{-\beta_{\mathrm{DEF}}}-\beta_{\mathrm{ABH}}-\beta_{\mathrm{FH}}$ \\
\hline 9 & $\operatorname{cdh}$ & $\beta_{\mathrm{CD}}+\beta_{\mathrm{BG}}-\beta_{\mathrm{AFG}}-\beta_{\mathrm{CEH}}$ & 2 & cde & $\beta_{\mathrm{CDE}}+\beta_{\mathrm{BEG}}-\beta_{\mathrm{CH}}$ \\
\hline 2 & acdfh & $\beta_{\mathrm{ACD}}+\beta_{\mathrm{ABG}}-\beta_{\mathrm{FG}}$ & 9 & acdef & $-\beta_{\mathrm{ACH}}-\beta_{\mathrm{EFG}}$ \\
\hline 10 & bcdfgh & $\beta_{\mathrm{BCD}}+\beta_{\mathrm{G}}$ & 1 & bcdefg & $\beta_{E G}-\beta_{\mathbf{B C H}}-\beta_{\mathrm{DGH}}$ \\
\hline 1 & abcdgh & ${ }^{-\beta_{\mathrm{CDF}}}+\beta_{\mathrm{AG}}-\beta_{\mathrm{BFG}}$ & 10 & abcdeg & $\left(\beta_{\mathrm{AEG}}+\beta_{\mathrm{CFH}}\right)^{\mathrm{c}}$ \\
\hline
\end{tabular}

${ }^{a}$ See fig. 1. 
TABLE X. - $(2,4)$ REPLICATE

$[\mathrm{I}=-\mathrm{ACDFG}=-\mathrm{BCEGH}=\mathrm{ABDEFH}$; blocking given by fig. 1; estimates confounded with column block differences have superscript $c$; estimates confounded with row block differences have superscript $r$.]

\begin{tabular}{|c|c|c|c|c|c|c|c|c|c|c|c|}
\hline Block & $\begin{array}{c}\text { Treat- } \\
\text { ment }\end{array}$ & Estimate & Block & $\begin{array}{c}\text { Treat- } \\
\text { ment }\end{array}$ & Estimate & Block & $\begin{array}{c}\text { Treat- } \\
\text { ment }\end{array}$ & Estimate & Block & $\begin{array}{l}\text { Treat- } \\
\text { ment }\end{array}$ & Estimate \\
\hline 1 & $(1)$ & $\beta_{\mathrm{I}}$ & 10 & eh & $\beta_{\mathrm{E}}$ & 12 & fgh & $\beta_{\mathrm{F}}$ & 3 & efg & $\beta_{E F}$ \\
\hline 3 & agh & $\beta_{\mathrm{A}}$ & 12 & aeg & $\beta_{\mathrm{AE}}$ & 10 & af & $\beta_{\mathrm{AF}}-\beta_{\mathrm{CDG}}$ & 1 & aefh & $\beta_{\mathrm{AEF}}+\beta_{\mathrm{BDH}}$ \\
\hline 11 & $\mathrm{bh}$ & $\beta_{\mathrm{B}}$ & 4 & be & $\beta_{\mathrm{BE}}-\beta_{\mathrm{CGH}}$ & 2 & bfg & $\beta_{\mathrm{BF}}$ & 9 & befgh & $\beta_{\mathrm{BEF}}+\beta_{\mathrm{ADH}}$ \\
\hline 9 & $\operatorname{abg}$ & $\beta_{\mathrm{AB}}$ & 2 & abegh & $\beta_{\mathrm{ABE}}+\beta_{\mathrm{DFH}}$ & 4 & abfh & $\left(\beta_{\mathrm{ABF}}+\beta_{\mathrm{DEH}}\right)^{\mathrm{c}}$ & 11 & abef & $\beta_{\mathrm{DH}}$ \\
\hline 10 & $\mathrm{cg}$ & $\beta_{C}$ & 1 & cegh & $\beta_{\mathrm{CE}}-\beta_{\mathrm{BGH}}$ & 3 & efh & $\beta_{C F}-\beta_{A D G}$ & 12 & cef & $\beta_{\mathrm{CEF}}$ \\
\hline 12 & $\operatorname{ach}$ & ${ }^{\beta} \mathrm{AC}^{-}{ }^{\beta} \mathrm{DFG}$ & 3 & ace & $\beta_{\mathrm{ACE}}$ & 1 & acfg & $\beta_{\mathrm{ACF}}-\beta_{\mathrm{DG}}$ & 10 & acefgh & ${ }^{-\beta} \mathrm{DEG}$ \\
\hline 4 & bcgh & $\beta_{\mathrm{BC}}-\beta_{\mathrm{EGH}}$ & 11 & bceg & $\beta_{\mathrm{BCE}}-\beta_{\mathrm{GH}}$ & 9 & bcf & $\beta_{\mathrm{BCF}}$ & 2 & bcefh & $\left(-\beta_{\mathrm{FGH}}\right)$ \\
\hline 2 & $a b c$ & $\beta_{\mathrm{ABC}}$ & 9 & abceh & $-\beta_{\mathrm{AGH}}$ & 11 & abcfgh & ${ }^{-\beta} \beta_{\mathrm{BDG}}$ & 4 & abcefg & $\beta_{\mathrm{CDH}}$ \\
\hline 2 & $\operatorname{dgh}$ & $\beta_{\mathrm{D}}$ & 9 & $\operatorname{deg}$ & $\beta_{\mathrm{DE}}$ & 11 & $\mathrm{df}$ & $\beta_{\mathrm{DF}}-\beta_{\mathrm{ACG}}$ & 4 & defh & $\beta_{\mathrm{DEF}}+\beta_{\mathrm{ABH}}$ \\
\hline 4 & $\mathrm{ad}$ & $\beta_{A D}-\beta_{C F G}$ & 11 & adeh & $\beta_{\mathrm{ADE}}+\beta_{\mathrm{BFH}}$ & 9 & adfgh & ${ }^{\beta} \mathrm{ADF}^{-\beta} \mathrm{CG}^{+\beta_{\mathrm{BEH}}}$ & 2 & adefg & $\beta_{\mathrm{BH}}-\beta_{\mathrm{CEG}}$ \\
\hline 12 & bdg & $\beta_{\mathrm{BD}}$ & 3 & bdegh & $\beta_{\mathrm{BDE}}+\beta_{\mathrm{AFH}}$ & 1 & bdfh & $\beta_{\mathrm{BDF}}+\beta_{\mathrm{AEH}}$ & 10 & bdef & $\beta_{\mathrm{AH}}$ \\
\hline 10 & abdh & $\beta_{\mathrm{ABD}}+\beta_{\mathrm{EFH}}$ & 1 & abde & $\beta_{\mathrm{FH}}$ & 3 & abdfg & $\beta_{\mathrm{EH}}-\beta_{\mathrm{BCG}}$ & 12 & abdefgh & $\beta_{\mathrm{H}}$ \\
\hline 9 & cdh & ${ }^{\beta} \mathrm{CD}-\beta_{\mathrm{AFG}}$ & 2 & cde & $\beta_{\mathrm{CDE}}$ & 4 & cdfg & $\beta_{\mathrm{CDF}}-\beta_{\mathrm{AG}}$ & 11 & cdefgh & $\left(-\beta_{\mathrm{AEG}}\right)^{c}$ \\
\hline 11 & acdg & $\beta_{\mathrm{ACD}}-\beta_{\mathrm{FG}}$ & 4 & acdegh & $-\beta_{E F G}$ & 2 & acdfh & $-\beta_{\mathrm{G}}$ & 9 & acdef & $-\beta_{\mathbf{E G}}-\beta_{\mathrm{BCH}}$ \\
\hline 3 & bcd & $\beta_{\mathrm{BCD}}$ & 12 & bcdeh & $-\beta \mathrm{DGH}$ & 10 & bcdfgh & $-\beta_{\mathrm{ABG}}$ & 1 & bcdefg & $\beta_{\mathrm{ACH}}$ \\
\hline 1 & abcdgh & $-\beta_{\mathrm{BFG}}$ & 10 & abcdeg & $\left(\beta_{\mathrm{CFH}}\right)^{\mathrm{c}}$ & 12 & abcdf & $-\beta_{\mathrm{BG}}+\beta_{\mathrm{CEH}}$ & 3 & abcdefh & $-\beta_{\mathrm{BEG}}+\beta_{\mathrm{CH}}$ \\
\hline
\end{tabular}


TABLE XI. - $(2,8)$ REPLICATE

[I = ABDEFH; blocking given by fig. 1; estimates confounded with column block differences have superscript c; estimates culfuunded with row block differences have superscript $r$.]

\begin{tabular}{|c|c|c|c|c|c|c|c|c|c|c|c|}
\hline Block & $\begin{array}{l}\text { Treat- } \\
\text { ment }\end{array}$ & Estimate & Block & $\begin{array}{c}\text { Treat- } \\
\text { ment }\end{array}$ & Estimate & Block & $\begin{array}{c}\text { Treat- } \\
\text { ment }\end{array}$ & Estimate & Block & $\begin{array}{c}\text { Treat- } \\
\text { ment }\end{array}$ & Estimate \\
\hline 1 & $(1)$ & $\beta_{\mathrm{I}}$ & 8 & $\mathrm{fh}$ & $\beta_{F}$ & 16 & g & $\beta_{\mathrm{G}}$ & 12 & fgh & $\beta_{\mathrm{FG}}$ \\
\hline 13 & ah & $\beta_{\mathrm{A}}$ & 10 & af & $\beta_{A F}$ & 3 & agh & $\beta_{\mathrm{AG}}$ & 7 & afg & $\beta_{\mathrm{AFG}}$ \\
\hline 11 & bh & $\beta_{\mathrm{B}}$ & 15 & bf & $\beta_{\mathrm{BF}}$ & 5 & bgh & $\beta_{\mathrm{BG}}$ & 2 & bfg & $\beta_{\mathrm{BFG}}$ \\
\hline 6 & $a b$ & $\beta_{\mathrm{AB}}$ & 4 & abfh & $\left(\beta_{\mathrm{ABF}}+\beta_{\mathrm{DEH}}\right)^{\mathrm{c}}$ & 9 & abg & $\beta_{\mathrm{ABG}}$ & 14 & abfgh & $\beta_{\mathrm{ABFG}}+\beta_{\mathrm{DEGH}}$ \\
\hline 7 & $\mathrm{c}$ & ${ }^{\beta} \mathrm{C}$ & 3 & cfh & $\beta_{\mathrm{CF}}$ & 10 & $\mathrm{cg}$ & ${ }^{\beta} \mathrm{CG}$ & 13 & efgh & ${ }^{\beta} \mathrm{CFG}$ \\
\hline 12 & ach & $\beta_{\mathrm{AC}}$ & 16 & acf & $\beta_{\mathrm{ACF}}$ & 8 & $\operatorname{acgh}$ & $\beta_{\mathrm{ACG}}$ & 1 & acfg & ${ }^{\beta} \mathrm{ACFG}$ \\
\hline 14 & bch & $\beta_{\mathrm{BC}}$ & 9 & bcf & $\beta_{\mathrm{BCF}}$ & 4 & bcgh & ${ }^{\beta} \mathrm{BCG}$ & 6 & bcfg & $\beta_{\mathrm{BCFG}}$ \\
\hline 2 & $a b c$ & $\beta_{\mathrm{ABC}}$ & 5 & abcfh & $\beta_{\mathrm{ABCF}}+\beta_{\mathrm{CDEH}}$ & 15 & abcg & $\beta_{\mathrm{ABCG}}$ & 11 & abcigh & ${ }^{\beta} \mathrm{ABCFG}+\beta_{\mathrm{CDEGH}}$ \\
\hline 15 & $\mathrm{dh}$ & $\beta_{D}$ & 11 & $\mathrm{df}$ & $\beta_{\mathrm{DF}}$ & 2 & dgh & $\beta_{D G}$ & 5 & dig & ${ }^{\beta} \mathrm{DFG}$ \\
\hline 4 & ad & $\beta_{\mathrm{AD}}$ & 6 & adfh & $\beta_{\mathrm{ADF}}+\beta_{\mathrm{BEH}}$ & 14 & adg & ${ }^{\beta} \mathrm{ADG}$ & 9 & adfgh & $\beta_{\mathrm{ADFG}}+\beta_{\mathrm{BEGH}}$ \\
\hline 8 & bd & ${ }^{\beta} \mathrm{BD}$ & 1 & bdfh & $\beta_{\mathrm{BDF}}+\beta_{\mathrm{AEH}}$ & 12 & bdg & $\beta_{\mathrm{BDG}}$ & 16 & bdfgh & $\beta_{\mathrm{BDFG}}+\beta_{\mathrm{AEGH}}$ \\
\hline 10 & abdh & $\beta_{\mathrm{ABD}}+\beta_{\mathrm{EFH}}$ & 13 & abdf & $\beta_{E H}$ & 7 & abdgh & $\beta_{\mathrm{ABDG}}+\beta_{\mathrm{EFGH}}$ & 3 & abdfg & $\beta_{E G H}$ \\
\hline 9 & cdh & ${ }^{\beta} \mathrm{CD}$ & 14 & $\operatorname{cdr}$ & $\beta_{\mathrm{CDF}}$ & 6 & edgh & ${ }^{\beta} \mathrm{CDG}$ & 4 & cdfg & ${ }^{\beta} \mathrm{CDFG}$ \\
\hline 5 & acd & $\beta_{\mathrm{ACD}}$ & 2 & acdfh & $\beta_{\mathrm{ACDF}}+\beta_{\mathrm{BCEH}}$ & 11 & $\operatorname{acdg}$ & ${ }^{\beta} \mathrm{ACDG}$ & 15 & acdfgh & $\left(\beta_{\mathrm{ACDFG}}+\beta_{\mathrm{BCEGH}}\right)^{c}$ \\
\hline 3 & bed & $\beta_{\mathrm{BCD}}$ & 7 & bcdfh & $\beta_{\mathrm{BCDF}}+\beta_{\mathrm{ACEH}}$ & 13 & bedg & $\left(\beta_{\mathrm{BCDG}}\right)^{\mathrm{c}}$ & 10 & bcdfgh & $\beta_{\mathrm{BCDFG}}+\beta_{\mathrm{ACEGH}}$ \\
\hline 16 & abcdh & $\beta_{\mathrm{ABCD}}+3 \mathrm{CEFH}$ & 12 & abcdf & $\beta_{\mathrm{CEH}}$ & 1 & abcdgh & $\beta_{\mathrm{ABCDG}}+\beta_{\mathrm{CEFGH}}$ & 8 & abcdfg & ${ }^{\beta} \mathrm{CEGH}$ \\
\hline 10 & eh & $\beta_{\mathrm{E}}$ & 13 & ef & $\beta_{E F}$ & 7 & egh & $\beta_{\mathrm{EG}}$ & 3 & efg & $\beta_{\mathrm{EFG}}$ \\
\hline 8 & $a e$ & $\beta_{A E}$ & 1 & aefh & $\beta_{\mathrm{AEF}}+\beta_{\mathrm{BDH}}$ & 12 & aeg & $\left(\beta_{\mathrm{AEG}}\right)^{\mathrm{c}}$ & 16 & aefgh & $\beta_{\mathrm{AEFG}}$ \\
\hline 4 & be & $\beta_{\mathrm{BE}}$ & 6 & befh & $\beta_{\mathrm{BEF}}+{ }^{\beta} \mathrm{ADH}$ & 14 & beg & ${ }^{\beta} \mathrm{BEG}$ & 9 & befgh & $\left(\beta_{\mathrm{BEFG}}+\beta_{\mathrm{ADGH}}\right)^{\mathrm{c}}$ \\
\hline 15 & abeh & $\beta_{\mathrm{ABE}}+\beta_{\mathrm{DFH}}$ & 11 & abef & $\beta_{\mathrm{DH}}$ & 2 & abegh & $\beta_{\mathrm{ABEG}}+\beta_{\mathrm{DFGH}}$ & 5 & abefg & $\beta_{\text {DGH }}$ \\
\hline 16 & ceh & $\beta_{\mathrm{CE}}$ & 12 & cef & $\beta_{\mathrm{CEF}}$ & 1 & cegh & ${ }^{\beta} \mathrm{CEG}$ & 8 & $\operatorname{cefg}$ & ${ }^{\beta} \mathrm{CEFG}$ \\
\hline 3 & ace & ${ }^{\beta} \mathrm{ACE}$ & 7 & acefh & $\beta_{\mathrm{ACEF}}+\beta_{\mathrm{BCDH}}$ & 13 & aceg & $\beta_{\mathrm{ACEG}}$ & 10 & acefgh & $\beta_{\mathrm{ACEFG}}+\beta_{\mathrm{BCDGH}}$ \\
\hline 5 & bce & $\beta_{\mathrm{BCE}}$ & 2 & bcefh & $\beta_{\mathrm{BCEF}}+\beta_{\mathrm{ACDH}}$ & 11 & bceg & $\beta_{\mathrm{BCEG}}$ & 15 & bcefgh & $/ \beta_{\mathrm{BCEFG}}+\beta_{\mathrm{ACDGH}}$ \\
\hline 9 & abceh & $\beta_{\mathrm{ABCE}}+\beta_{\mathrm{CDFH}}$ & 14 & abcef & $\beta_{\mathrm{CDH}}$ & 6 & abcegh & $\beta_{\mathrm{ABCEG}}+\beta_{\mathrm{CDFGH}}$ & 4 & abcefg & $\beta^{\beta} \mathrm{CDGH}$ \\
\hline 6 & de & ${ }^{\beta} \mathrm{DE}$ & 4 & defh & $\beta_{\mathrm{DEF}}+\beta_{\mathrm{ABH}}$ & 9 & $\operatorname{deg}$ & $\beta_{\mathrm{DEG}}$ & 14 & defgh & $\beta_{\mathrm{DEFG}}+\beta_{\mathrm{ABGH}}$ \\
\hline 11 & adeh & $\beta_{\mathrm{ADE}}+\beta_{\mathrm{BFH}}$ & 15 & adef & ${ }^{\beta} \mathrm{BH}$ & 5 & adegh & $\beta_{\mathrm{ADEG}}+\beta_{\mathrm{BFGH}}$ & 2 & adefg & $\beta_{\mathrm{BGH}}$ \\
\hline 13 & bdeh & $\beta_{\mathrm{BDE}}+\beta_{\mathrm{AFH}}$ & 10 & bdef & $\beta_{\mathrm{AH}}$ & 3 & bdegh & $\beta_{\mathrm{BDEG}}+\beta_{\mathrm{AFGH}}$ & 7 & bdefg & $\beta_{\mathrm{AGH}}$ \\
\hline 1 & abde & $\beta_{\mathrm{FH}}$ & 8 & abdefh & $\beta_{\mathrm{H}}$ & 16 & abdeg & $\left(\beta_{F G H}\right)^{r}$ & 12 & abdefgh & $\beta_{\mathrm{GH}}$ \\
\hline 2 & cde & ${ }^{\beta} \mathrm{CDE}$ & 5 & cdefh & $\left(\beta_{\mathrm{CDEF}}+\beta_{\mathrm{ABCH}}\right)^{\mathrm{C}}$ & 15 & cdeg & $\beta_{\mathrm{CDEG}}$ & 11 & cdefgh & ${ }^{\beta} \mathrm{CDEFG}+\beta_{\mathrm{ABCGH}}$ \\
\hline 14 & acdeh & $\beta_{\mathrm{ACDE}}+\beta_{\mathrm{BCFH}}$ & 9 & acdef & ${ }^{\beta} \mathrm{BCH}$ & 4 & acdegh & $\beta_{\mathrm{ACDEG}}+\beta_{\mathrm{BCF} \mathrm{GH}}$ & 6 & acdeig & $\beta_{\mathrm{BCGH}}$ \\
\hline 12 & bedeh & $\beta_{\mathrm{BCDE}}+\beta_{\mathrm{ACFH}}$ & 16 & bcdef & $\beta_{\mathrm{ACH}}$ & 8 & bcdegh & $\beta_{\mathrm{BCDEG}}+\beta_{\mathrm{ACFGH}}$ & 1 & bedefg & $\beta_{\mathrm{ACGH}}$ \\
\hline 7 & abcde & $\left(\beta_{\mathrm{CFH}}\right)^{\mathrm{C}}$ & 3 & abcdeff & $\beta_{\mathrm{CH}}$ & 10 & abcdeg & $\beta_{\mathrm{CFGH}}$ & 13 & abcdefgh & $\beta_{\mathrm{CGH}}$ \\
\hline
\end{tabular}


TABLE XII. - ASSIGNMENT OF TREATMENTS TO BLOCKS

[(16/32) replicate; I = ABDEFH. ]

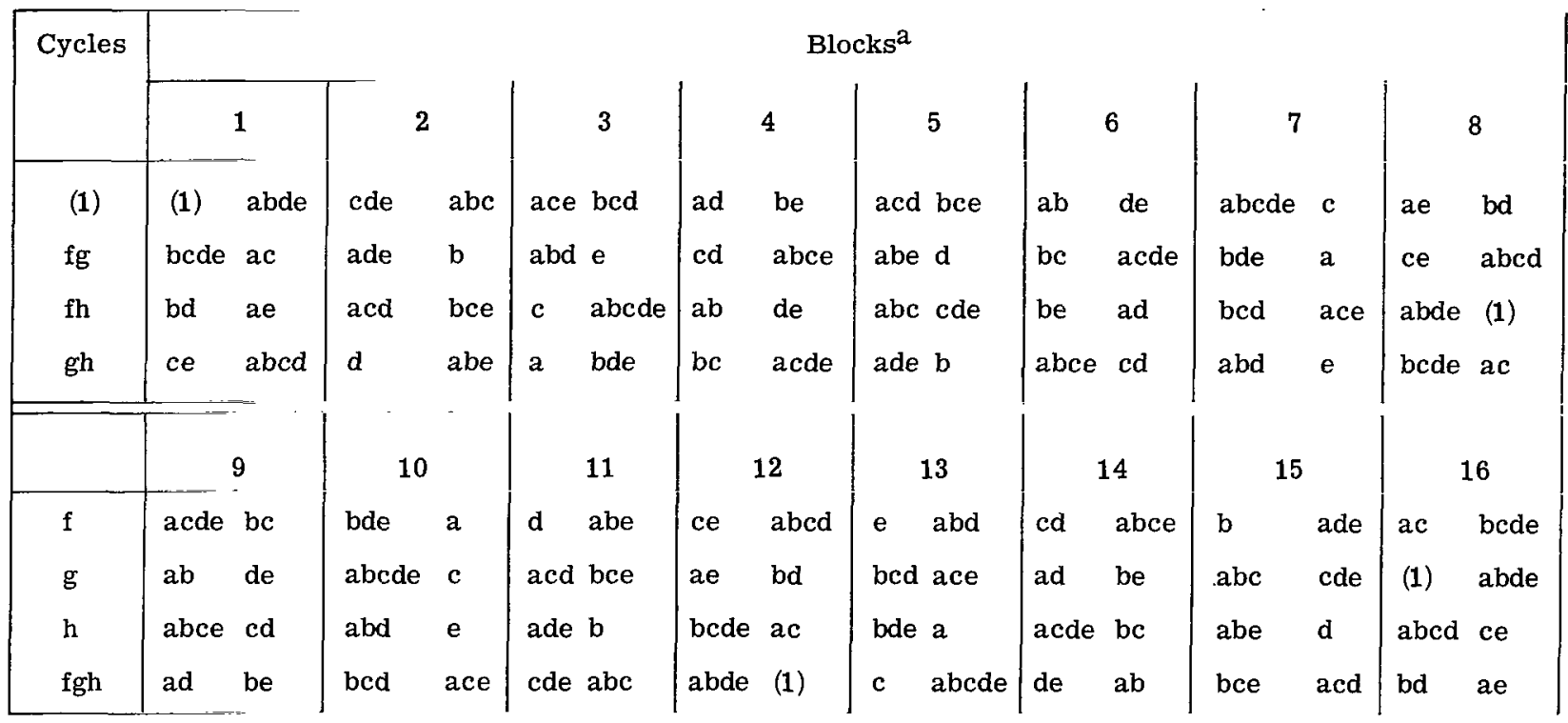

${ }^{a}$ See fig. 1. 
TABLE XIII. - NUMBER OF BLOCKS AT WHICH COEFFICIENT FIRST BECOMES ESTIMABLE

[Estimates confounded with column block differences have superscript $\mathbf{c}$; estimates confounded with row block differences have superscript $\mathrm{r}$.]

\begin{tabular}{|c|c|c|c|c|c|c|c|c|c|c|c|c|c|c|c|c|c|c|c|c|}
\hline $\begin{array}{l}\text { Coeffi- } \\
\text { cient }\end{array}$ & $\begin{array}{c}\text { First } \\
\text { row }\end{array}$ & $\begin{array}{l}\text { Two } \\
\text { rows }\end{array}$ & $\begin{array}{l}\text { Coeffi- } \\
\text { cient }\end{array}$ & $\begin{array}{c}\text { First } \\
\text { row }\end{array}$ & $\begin{array}{l}\text { Two } \\
\text { rows }\end{array}$ & $\begin{array}{c}\text { Coeffi- } \\
\text { cient }\end{array}$ & $\begin{array}{c}\text { First } \\
\text { row }\end{array}$ & $\begin{array}{l}\text { Two } \\
\text { rows }\end{array}$ & $\begin{array}{l}\text { Coeffi- } \\
\text { cient }\end{array}$ & $\begin{array}{l}\text { First } \\
\text { row }\end{array}$ & $\begin{array}{l}\text { Two } \\
\text { rows }\end{array}$ & $\begin{array}{c}\text { Coeffi- } \\
\text { cient }\end{array}$ & $\begin{array}{c}\text { First } \\
\text { row }\end{array}$ & $\begin{array}{l}\text { Two } \\
\text { rows }\end{array}$ & $\begin{array}{c}\text { Coeffi- } \\
\text { cient }\end{array}$ & $\begin{array}{c}\text { First } \\
\text { row }\end{array}$ & $\begin{array}{l}\text { Two } \\
\text { rows }\end{array}$ & $\begin{array}{c}\text { Coeffi- } \\
\text { cient }\end{array}$ & $\begin{array}{c}\text { First } \\
\text { row }\end{array}$ & $\begin{array}{l}\text { Two } \\
\text { rows }\end{array}$ \\
\hline$\beta_{\mathrm{I}}$ & 1 & 2 & $\beta_{\mathrm{AB}}$ & 4 & 8 & $\beta_{\mathrm{CE}}$ & 8 & 4 & ${ }^{\beta} \mathrm{ABC}$ & 8 & 8 & $\beta_{\mathrm{ADH}}$ & & & $\beta_{\text {BDG }}$ & & 8 & ${ }^{\beta} \mathrm{CEH}$ & 8 & 16 \\
\hline$\beta_{\mathrm{A}}$ & 1 & 2 & $\beta_{\mathrm{AC}}$ & 8 & 4 & $\beta_{\mathrm{CF}}$ & 8 & 4 & $\beta_{\mathrm{ABD}}$ & & & $\beta_{\mathrm{AEF}}$ & & & ${ }^{\beta} \mathrm{BDH}$ & & & ${ }^{\beta} \mathrm{CFG}$ & & 16 \\
\hline$\beta_{\mathrm{B}}$ & 2 & 2 & $\beta_{\mathrm{AD}}$ & 8 & 4 & ${ }^{\beta} \mathrm{CG}$ & $4^{c}$ & 8 & $\beta_{\mathrm{ABE}}$ & & & ${ }^{\beta} \mathrm{AEG}$ & & $8^{c}$ & ${ }^{\beta} \mathrm{BEF}$ & & & ${ }^{\beta} \mathrm{CFH}$ & & $8^{c}$ \\
\hline${ }^{\beta} \mathrm{C}$ & 2 & 2 & ${ }^{\beta} \mathrm{AE}$ & 4 & 4 & ${ }^{\beta} \mathrm{CH}$ & 8 & 4 & ${ }^{\beta} \mathrm{ABF}$ & & & $\beta_{\mathrm{AEH}}$ & & & $\beta_{\mathrm{BEG}}$ & & 16 & ${ }^{\beta} \mathrm{CGH}$ & & 16 \\
\hline$\beta_{\mathrm{D}}$ & 2 & 2 & $\beta_{\mathrm{AF}}$ & 4 & 8 & ${ }^{\beta} \mathrm{DE}$ & 4 & 8 & $\beta_{\mathrm{ABG}}$ & & 8 & $\beta_{\mathrm{AFG}}$ & & 16 & $\beta_{\mathrm{BEH}}$ & & & $\beta_{\mathrm{DEF}}$ & & \\
\hline$\beta_{\mathrm{E}}$ & 1 & 2 & $\beta_{\mathrm{AG}}$ & 4 & 4 & ${ }^{\beta} \mathrm{DF}$ & 4 & 4 & $\beta_{\mathrm{ABH}}$ & & & $\beta_{\mathrm{AFH}}$ & & & $\beta_{\mathrm{BFG}}$ & & 8 & $\beta_{\mathrm{DEG}}$ & & 8 \\
\hline$\beta_{F}$ & 1 & 2 & ${ }^{\beta} \mathrm{AH}$ & 8 & 4 & ${ }^{\beta} \mathrm{DG}$ & 4 & 8 & $\beta_{\mathrm{ACD}}$ & 8 & 16 & $\beta_{\mathrm{AGH}}$ & & 8 & $\beta_{\mathrm{BFH}}$ & & & $\beta_{\mathrm{DEH}}$ & & \\
\hline$\beta_{\mathrm{G}}$ & 2 & 2 & $\beta_{\mathrm{BC}}$ & 8 & 8 & ${ }^{\beta} \mathrm{DH}$ & 8 & 8 & $\beta_{\mathrm{ACE}}$ & $8^{c}$ & 8 & $\beta_{\mathrm{BCD}}$ & 8 & 8 & $\beta_{\mathrm{BGH}}$ & & 16 & $\beta_{\mathrm{DFG}}$ & & 16 \\
\hline \multirow[t]{6}{*}{$\beta_{\mathrm{H}}$} & 1 & 2 & ${ }^{\beta} \mathrm{BD}$ & $4^{c}$ & 8 & $\beta_{\mathbf{E F}}$ & 8 & 4 & $\beta_{\mathrm{ACF}}$ & 8 & 16 & $\beta_{\mathrm{BCE}}$ & 8 & 16 & ${ }^{\beta} \mathrm{CDE}$ & 8 & 16 & $\beta_{\mathrm{DFH}}$ & & \\
\hline & & & $\beta_{\mathrm{BE}}$ & 8 & 4 & $\beta_{\mathrm{EG}}$ & 4 & 4 & $\beta_{\mathrm{ACG}}$ & 8 & 16 & $\beta_{\mathrm{BCF}}$ & 8 & 8 & ${ }^{\beta} \mathrm{CDF}$ & 8 & 16 & $\beta_{\mathrm{DGH}}$ & & 8 \\
\hline & & & $\beta_{\mathrm{BF}}$ & 8 & 8 & $\beta_{\mathbf{E H}}$ & 4 & 8 & ${ }^{\beta} \mathrm{ACH}$ & 8 & 8 & $\beta_{\mathrm{BCG}}$ & 8 & 16 & ${ }^{\beta} \mathrm{CDG}$ & 8 & 16 & ${ }^{\beta}$ EFG & & 8 \\
\hline & & & $\beta_{\mathrm{BG}}$ & 4 & 8 & $\beta_{\mathbf{F G}}$ & & 4 & ${ }^{\beta} \mathrm{ADE}$ & & & $\beta_{\mathrm{BCH}}$ & 8 & 16 & ${ }^{\beta} \mathrm{CDH}$ & 8 & 8 & $\beta_{\mathrm{EFH}}$ & & \\
\hline & & & $\beta_{\mathrm{BH}}$ & 4 & 4 & $\beta_{\mathbf{F H}}$ & & 4 & $\beta_{\mathrm{ADF}}$ & & & $\beta_{\mathrm{BDE}}$ & & & ${ }^{\beta}$ CEF & 8 & 8 & $\beta_{\text {EGH }}$ & & 16 \\
\hline & & & ${ }^{\beta} \mathrm{CD}$ & 8 & 8 & $\beta_{\mathrm{GH}}$ & & 4 & ${ }^{\beta} \mathrm{ADG}$ & & 16 & $\beta_{\mathrm{BDF}}$ & & & $\beta_{\mathrm{CEG}}$ & 8 & 16 & $\beta_{\text {FGH }}$ & & $8^{r}$ \\
\hline
\end{tabular}


TABLE XIV. - NUMBER OF INTERACTION PARAMETERS ESTIMABLE AT

SUCCESSIVE STAGES OF TELESCOPING SEQUENCES

\begin{tabular}{|c|c|c|c|c|c|c|}
\hline \multirow[t]{3}{*}{$\begin{array}{l}\text { Interaction } \\
\text { coefficient }\end{array}$} & \multirow{3}{*}{$\begin{array}{l}\text { Number of } \\
\text { interactions } \\
\text { in the } \\
\text { complete } \\
\text { model }\end{array}$} & \multicolumn{5}{|c|}{$\begin{array}{l}\text { Number of interaction parameters estimable after } \\
\text { completing the following number of blocks }\end{array}$} \\
\hline & & \multicolumn{2}{|c|}{ First row } & \multicolumn{3}{|c|}{ Two rows } \\
\hline & & 4 & 8 & 4 & 8 & 16 \\
\hline Two factor & 28 & $a_{13}$ & $\mathrm{a}_{25}$ & 16 & 28 & 28 \\
\hline Three factor & 56 & 0 & $\mathrm{~b}_{18}$ & 0 & $\mathrm{a}, \mathrm{c}_{17}$ & $\mathrm{a}, \mathrm{c}_{36}$ \\
\hline
\end{tabular}

${ }^{a}$ Includes two parameters confounded with column differences.

${ }^{b}$ Includes one parameter confounded with column differences.

${ }^{\mathrm{c}}$ Includes one parameter confounded with row differences. 


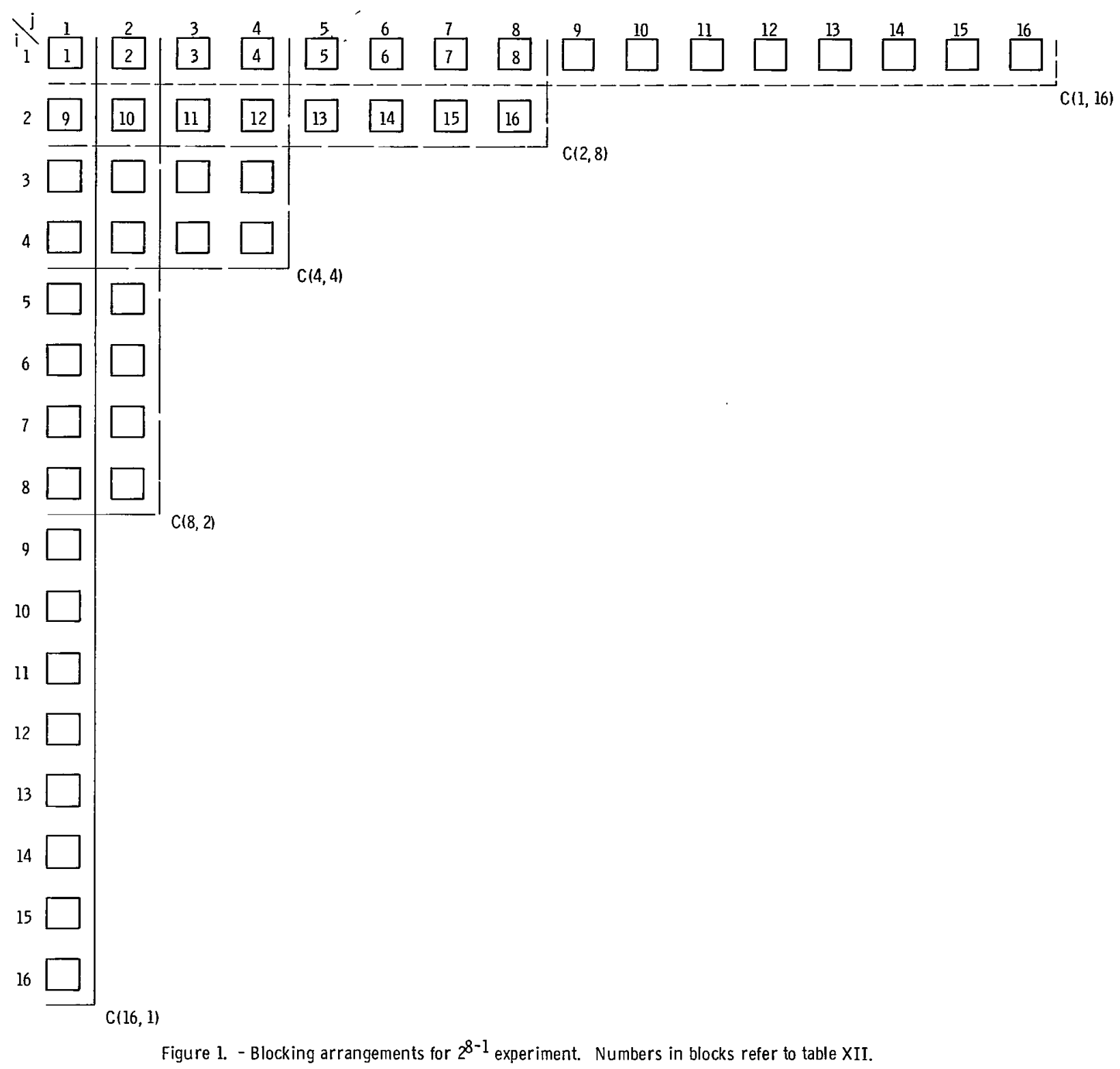


National Aeronautics and Space administration

WASHINGTON, D. C. 20546

OFFICIAL BUSINESS
FIRST CLASS MAIL

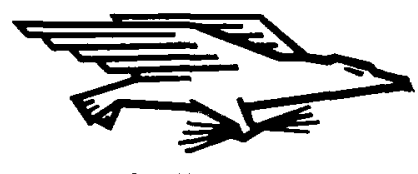

POSTAGE AND FEES PAID NATIONAL AERONAUTICS AND SPACE ADMINISTRATION

POSTMASTER: If Undeliverable (Section 158 If Undeliverable (Section 158
Postal Manual) Do Not Rerurn

"The aeronantical and space activities of the United States shall be conducted so as to contribute. . . to the expansion of buman knowledge of phenomena in the atmospbere and space. The Administration shall provide for the widest practicable and appropriate dissemination of information concerning its activities and the results thereof."

- National Aeronautics and Space ACt of 1958

\section{NASA SCIENTIFIC AND TECHNICAL PUBLICATIONS}

TECHNICAL REPORTS: Scientific and technical information considered important, complete, and a lasting contribution to existing knowledge.

TECHNICAL NOTES: Information less broad in scope but nevertheless of importance as a contribution to existing knowledge.

\section{TECHNICAL MEMORANDUMS:}

Information receiving limited distribution because of preliminary data, security classification, or other reasons.

CONTRACTOR REPORTS: Scientific and technical information generated under a NASA contract or grant and considered an important contribution to existing knowledge.
TECHNICAL TRANSLATIONS: Information published in a foreign language considered to merit NASA distribution in English.

SPECIAL PUBLICATIONS: Information derived from or of value to NASA activities. Publications include conference proceedings, monographs, data compilations, handbooks, sourcebooks, and special bibliographies.

TECHNOLOGY UTILIZATION

PUBLICATIONS: Information on technology used by NASA that may be of particular interest in commercial and other non-aerospace applications. Publications include Tech Briefs, Technology Utilization Reports and Notes, and Technology Surveys.

Details on the availability of these publications may be obtained from:

\section{SCIENTIFIC AND TECHNICAL INFORMATION DIVISION}

NATIONAL AERONAUTICS AND SPACE ADMINISTRATION

Washington, D.C. 20546 